\title{
Liver cancer mortality over six decades in an epidemic area: What we have learned
}

\author{
Jian-Guo Chen ${ }^{\text {Corresp., } 1,2}{ }$, Jian Zhu ${ }^{1}$, Yong-Hui Zhang ${ }^{1}$, Yong-Sheng Chen ${ }^{1}$, Jian-Hua Lu ${ }^{1}$, Yuan-Rong Zhu ${ }^{1}$, Hai-Zhen \\ Chen $^{2}$, Ai-Guo Shen ${ }^{2}$, Gao-Ren Wang ${ }^{2}$, John D Groopman ${ }^{3}$, Thomas W Kensler ${ }^{\text {Corresp. } 3,4}$ \\ ${ }^{1}$ Department of Epidemiology, Qidong Liver Cancer Institute / Qidong People Hospital / Affiliated Qidong Hospital of Nantong University, Qidong, Jiangsu, \\ China \\ 2 Department of Epidemiology, Affiliated Tumor Hospital of Nantong University, Nantong, Jiangsu, China \\ 3 Bloomberg School of Public Health, The Johns Hopkins University, Baltimore, MD, United States \\ 4 Public Health Sciences Division, Fred Hutchinson Cancer Research Center, Seattle, WA, United States \\ Corresponding Authors: Jian-Guo Chen, Thomas W Kensler \\ Email address: chenjg@ntu.edu.cn, tkensler@fredhutch.org
}

Background and aims: Liver cancer is one of the most dominant malignant tumors in the world. The trends of liver cancer mortality over the past six decades have been tracked in the epidemic region of Qidong, China. Using epidemiological tools, we explore the dynamic changes in age-standardized rates to characterize important aspects of liver cancer etiology and prevention. Methods: Mortality data of liver cancer in Qidong from 1958 to 1971 (death retrospective survey) and from 1972 to 2017 (cancer registration) were tabulated for the crude rate $(C R)$, and age-standardized rate and age-birth cohorts. The average annual percentage change was calculated by the Joinpoint Regression Program. Results: The natural death rate during 1958-2017 decreased from 9\%o to 5.4\%o and then increased to $8 \%$ as the population aged; cancer mortality rates rose continuously from $57 / 105$ to $240 / 105$. Liver cancer mortality increased from $20 / 105$ to $80 / 105$, and then dropped to less than 52/105 in 2017. Liver cancer deaths in 1972-2017 accounted for $30.53 \%$ of all cancers, with a CR of $60.48 / 105$, age-standardized rate (ASRC) China of 34.78/105, and ASRW (world) of 45.71/105. Other key features were the CR for males and females of $91.86 / 105$ and 29.92/105, respectively, with a sex ratio of 3.07:1. Period analysis showed that the ASRs for mortality of the age groups under 54 years old had a significant decreasing trend. Importantly, birth cohort analysis showed that the mortality rate of liver cancer in 40-44, 35-39, 30-34, 25-29, 20-24, 15-19 years cohort decreased considerably, but the rates in 70-74, and 75+ increased. Conclusions: The crude mortality rate of liver cancer in Qidong has experienced trends from lower to higher levels, and from continued increase at a high plateau to most recently a gradual decline, and a change greatest in younger people. Many years of comprehensive prevention and intervention measures have influenced the decline of the liver cancer epidemic in this 
area. The reduction of intake levels of aflatoxin might be one of the most significant factors as evidenced by the dramatic decline of exposure biomarkers in this population during the past 3 decades.Liver cancer is one of the most dominant malignant tumors in the world. The trends of liver cancer mortality over the past six decades have been tracked in the epidemic region of Qidong, China. Using epidemiological tools, we explore the dynamic changes in age-standardized rates to characterize important aspects of liver cancer etiology and prevention. 


\section{Liver cancer mortality over six decades in an epidemic} 3 area: What we have learned

5 Jian-Guo Chen ${ }^{1,2 *}$, Jian Zhu ${ }^{1}$, Yong-Hui Zhang ${ }^{1}$, Yong-Sheng Chen ${ }^{1}$, Jian-Hua Lu', Yuan-

6 Rong Zhu ${ }^{1}$, Hai-Zhen Chen ${ }^{2}$, Ai-Guo Shen ${ }^{2}$, Gao-Ren Wang², John D. Groopman ${ }^{3}$, Thomas

7 W. Kensler ${ }^{3,4 *}$

8

$9 \quad{ }^{1}$ Qidong Liver Cancer Institute / Qidong People Hospital / Affiliated Qidong Hospital of 10 Nantong University, Qidong, Jiangsu, P.R. China

112 Affiliated Tumor Hospital of Nantong University, Nantong, Jiangsu, P.R. China

$12{ }^{3}$ Johns Hopkins Bloomberg School of Public Health, Baltimore, MD, USA

${ }^{4}$ Fred Hutchinson Cancer Research Center, Seattle, WA, USA

Corresponding Authors:

16 Jian-Guo Chen ${ }^{1,2}$

17785 Jianghai Zhong Road, Qidong, Jiangsu, 226200, P.R. China

18 Email address: chenjg@ntu.edu.cn

Thomas W. Kensler 3,4 M5-A883, 1100 Fairview Ave N, Seattle, WA 98109, USA

Email address: tkensler@fredhutch.org

\section{Introduction}

Liver cancer is one of the most dominant malignant tumors in the world. According to GLOBOCAN 2018 [1], it was estimated that the incident cases of liver cancer was 841,080, which accounted for $4.65 \%$ out of $18,078,957$ malignant tumors in the world every year, ranking sixth in the world (fifth in men and ninth in women). Among 9,555,027 deaths with cancer, 781,631 cases $(8.18 \%)$ died of liver cancer, ranking fourth in the world (second in men and sixth in women) [1]. In 2017, incident cases of liver cancer in China were about 441,200, and the number of deaths were 395,200 [2], implying that the proportion of incident cases and death cases of liver cancer in China accounts for $52.46 \%$, and $50.56 \%$, respectively, of the global burden. In particular, liver cancer has among the poorest prognosis of all cancers. For instance, according to data of 291 cancer registries in 61 countries and regions in the CONCORD 3 Study 
35 [3], the 5-year survival rate of liver cancer was 5\%-30\% in $2000-2014$, and only $10 \%-19 \%$ in

36 Europe and America; while the 5-year survival rates in China in 2006-2008, 2009-2012, 2013-

372015 were $10.1 \%, 9.8 \%$ and $12.1 \%$, respectively [4]. In another research report in 2017, it was

38 estimated that the global disability-adjusted life years (DALYs) was 20.8 million, of which 99\%

39 was years of life lost (YLLs) due to early death and 1\% was years lived with disability (YLDs)

40 [5]. Thus, liver cancer constitutes a serious disease burden both in the whole world and in China,

41 and the study of liver cancer in China is of great significance for global cancer control.

42 Since the 1970s in China, a series of systematic studies on the epidemiology, etiology and

43 prevention of liver cancer have been carried out, and great progress has been made. Among

44 them, the prevention and treatment of liver cancer in Qidong, formerly a county and now a city

45 in Jiangsu Province, has been most representative [6,7]. This paper summarizes the trend of liver

46 cancer mortality over the past 60 years in Qidong according to a death retrospective survey and,

47 subsequently, a cancer registration report system, and makes an analysis and evaluation on the

48 related challenges and progress in the study of the etiology and prevention of this disease. As

49 such, it demonstrates that the age-standardized trajectories of dominant, often fatal cancers can

50 be attenuated dramatically with better understandings of underlying etiologies and

51 implementation of cancer control programs.

52

53

54

55

56

57

58

59

60

61

62

63

64

65

\section{Materials \& Methods}

\section{Retrospective survey of death}

During the period of July to August 1972, a 14-year retrospective survey (1958-1971) of cancer was organized among the 1.03 million residents in Qidong in order to understand the prevalence of liver cancer in this area [6]. At that time, the investigation teams were composed of cadres of brigade (village) doctors, barefoot doctors (grassroots medical staff), county hospital doctors, and medical team members (from hospitals / research institutes / universities in Shanghai and Jiangsu, Province). The investigation was carried out in the form of an investigational forum, usually with 3-5 "old" peasants and cadres in each brigade (village) [8].

The information in the questionnaire included address, name, gender, age at/and the date of death, cause of the death and/or the main symptoms (if any), and the diagnosis. For suspected cancer deaths, especially liver cancer, double checking of the cause would be performed with their family members or relatives. The survey showed that most of the cases were diagnosed and treated before death. In 1971, for example, $31.25 \%$ of the cases with liver cancer were diagnosed 
66 by the Shanghai Cancer Hospital and/or other provincial and municipal hospitals; $50.20 \%$ of the 67 cases were diagnosed by the Qidong People's Hospital or the Affiliated Hospitals of Nantong 68 Medical College; 14.17\% were diagnosed in district and/or commune (township) hospitals; only $694.38 \%$ were not identified in diagnosis units (unknown).

70

71

72 73

74

75 76 77 78 79 80

\section{Cancer registration report}

The Qidong Cancer Registry was established in 1972, covering the whole Qidong area and all of the registered population. All malignant tumors, including brain and central nervous system tumors, have been included and registered [8]. The International Classification of Diseases (ICD) 8th edition (ICD-8) was used for cancer cases before 1979, ICD-9 was used for the years 1979-2000, and ICD-10 was used for coding after 2000. Liver cancer was 155.0-155.9 in ICD-8 and ICD-9, and C22.0-22.9 in ICD-10. All data used in this database have been recoded as $\mathrm{C} 22.0-22.9$ according to ICD-10.

In 1990, the Qidong Cancer Registry was admitted to the International Cancer Registration Association (IACR) as a voting member unit. Some of data after 1983 were published in "Cancer Incidence in Five Continents (CI5)" by the International Agency on Cancer Research (IARC) $[9,10]$, or "Annual Report on Cancer of China" by the National Cancer Registry Center of China $[11,12]$. Most of the liver cancer cases in Qidong were diagnosed by alpha-fetoprotein (AFP) and / or B-ultrasound $(85.81 \%)$, and were verified by histology $(12.36 \%)$. Almost all cases $(98.17 \%)$ were defined by at least one of the three diagnostic criteria; classification by death certificate only (DCO) were only $0.34 \%$.

\section{Population information}

Information regarding the population of Qidong has come from the Residents Household Annual Report of the Qidong Public Security Bureau. The population size in Qidong has exceeded $1 \mathrm{M}$ since the 1970's; and reached a level of 1.12M in 2017. The age structure of the Qidong population in the years after 1972 have come from several sources: sampling survey in 1976 (ps1976), the third (national) census in 1982 (ps1982), the fourth census in 1990 (ps1990), the fifth census in 2000 (ps2000) and the sixth census in 2010 (ps2010). Hence, the population numbers of the age-groups from 1972 to 1976 were extrapolated according to the population structure of ps1976; the population age-group from 1982 to 1990 was extrapolated according to the population structure of ps1982 and ps1990; and the same method was used to extrapolate the population numbers of age-groups by period through the structures of two adjacent censuses. 


\section{Statistical methods}

For the period of 1958-1971, the Qidong death retrospective survey data [6] were used to calculate the natural death rate, cancer mortality and liver cancer mortality. For the period of 1972-2017, the natural death rate came from the Qidong Vital Registry. The other statistical indicators were calculated based upon the registered data, which included the crude mortality rate (CR), age-specific mortality rate, sex-specific mortality rate, truncated rate of 35-64, cumulative rate $0-74$, and cumulative risk; and birth cohort analysis was performed. The agespecific mortality rate was calculated as an average level for each five-year period (following the period compilated in CI5 $[9,10])$. The age-standardized rates were calculated by the China population in 1964 (ASRC) and by the world population in 1960 (ASRW), respectively. The growth rate of the two years $(\mathrm{y}, \mathrm{y}-1)$ at the end of the period compared with the two years $(\mathrm{x}, \mathrm{x}+$ 1) at the beginning of the period was evaluated by the percentage change (PC) of the rate (r): $P C_{x-y}=\left\{\left[\left(r_{y}+r_{y-1}\right)-\left(r x+r_{x+1}\right)\right] /\left(r_{x}+r_{x+1}\right)\right\} \times 100$ [13]. The Joinpoint Regression Program 4.7.0.0 (2019) was used to estimate the annual percent change (APC), average annual percent change (AAPC) and APC of each age group, allowing for the average increasing/decreasing trends of the rates to be evaluated $[14,15]$.

\section{Results}

\section{Natural death rate, mortality rates of cancer and liver cancer in Qidong}

According to the data from this period of six decades, the natural mortality rates in Qidong residents have experienced progressions from high to low, and then from low to high; the mortality rate between 1958 and 1960 was about 900/105 (9\%o), which dropped to its lowest of $540 / 10^{5}(5.4 \%$ o $)$ in the middle and late 1970 s, and then slowly increased back to about $900 / 10^{5}$ (9\%o) at the end of the period (2015-2017). Mortality rates of cancer combined increased slowly from $57 / 10^{5}$ in 1958 to $200 / 10^{5}$ in 1995 now exceed $300 / 10^{5}$. The mortality rate of liver cancer increased from $20 / 10^{5}$ in 1958 to about $50 / 10^{5}$ in the 1970 s, then fluctuated towards about $70 / 10^{5}$ in the late 1990s and then at the beginning of this century, moved towards $80 / 10^{5}$ in 2008 , before decreasing continuously, now approaching 52/105 (Figure 1).

\section{Liver cancer mortality, cumulative mortality and truncated rate}

Cancer registration data after 1972 were used to evaluate accurately the proportion of liver cancer hazard within total cancer deaths. The average crude mortality rate of liver cancer was $58.86 / 10^{5}$, while deaths due to liver cancer accounted for $30.53 \%(31,261 / 102,390$ total cases), 
128 and the truncated mortality rate of 35-64 years old was $104.06 / 10^{5}$, the cumulative mortality rate 129 of 0-74 years old was $4.79 \%$, and the cumulative risk of liver cancer was $4.68 \%$. The mortality 130 rates and other evolution indicators over the years for liver cancer in Qidong are shown in Table 1311.

\section{$132 \quad$ Trend of liver cancer mortality}

133 From 1972 to 2017, the crude mortality rate of liver cancer in Qidong increased by $134+17.78 \%$ in PC, and $+0.88 \%$ in APC; But, the ASRC and ASRW decreased by $-61.25 \%$ and $13551.43 \%$ in PC, and $-1.80 \%$ and $-1.35 \%$ in APC, respectively, showing a clear downward trend. 136 Analysis using the Joinpoint Regression Program showed that the average annual percent change 137 (AAPC) of ASRW was -1.3\% (95\% CI: $-1.6 \%,-1.1 \%$ ), in which -1.5\% (95\% CI: $-1.7 \%,-1.2 \%$ ) 138 was for men and $-1.0 \%$ (95\% CI: $-1.3 \%,-0.7 \%)$ was for women, as shown in Figure 2 and Table 1392.

140 Turning point analysis of multiple models showed that the trend in ASRW of liver cancer 141 during the 45 years of registration in Qidong could be divided into three joinpoints (four 142 periods), i.e., 1972-1992, 1992-1995, 1995-2006 and 2006-2017. Each of the APCs was -1.39\%, $143+4.50 \%,-1.42 \%$ and $-4.66 \%$, respectively. For men, it was one point ( 2 periods): $1972-2005$ and 144 2005-2017, APCs were $-0.48 \%$ and $-4.51 \%$, highlighting a significant downward trend. For 145 women, four joinpoints (5 periods) were identified: 1972-1986, 1986-1989, 1989-1994, 19941462008 and 2008-2017, APCs were $-0.42 \%,-11.52 \%,+7.68 \%,-1.13 \%$ and $-4.74 \%$, respectively, 147 indicating that the APC of the last period had a significant downward trend (Figure 3 ). The 148 results given by the multiple models showed that the AAPCs for men, women and both sexes 149 were $-1.8 \%$ (95\% CI: $-2.2 \%,-1.5 \%),-1.4 \%$ (95\% CI: $-3.5 \%, 0.7 \%)$ and $-1.8 \%$ (95\% CI: $-2.8 \%$, $1500.8 \%$ ), respectively, as shown in Table 2.

Crude mortality, standardized mortality of liver cancer by gender

The mortality rates of liver cancer over time in Qidong have been relatively stable; gender differences always higher in males than in females. From 1972 to 2007, the crude mortality rate of liver cancer was $91.86 / 10^{5}$ in men and $29.92 / 10^{5}$ in women, with a sex ratio of $3.07: 1$. For ASRC and ASRW, the sex ratio was 3.48:1 and 3.32:1, respectively. The crude mortality rates by sex and by year are listed in Table 3 . 
158

159

160

161

162

163

164

165

166

167

168

169

170

171

172

173

174

175

176

177

178

179

180

181

182

183

184

185

186

187

188

The mortality rate of liver cancer increased with age. At the age group of 35-39, the rate $\left(67.59 / 10^{5}\right)$ exceeded the average mortality level $\left(58.86 / 10^{5}\right)$ in the population. Mortality rates at all age groups over 40 remained at levels of around 110/105, and dropped to less than 90/10 at the age group of 80-84. Rates in all age groups were also higher in men than in women. From 1972 to 2017, the average age of death of liver cancer in Qidong was 53.71 years old, but showing a 5-year difference by gender: men 52.41 and women 57.58. It was observed that the average age of death for both sexes was under 50 years each year before 1993 (reaching a low of 48); since 1993, age of death of liver cancer has increased rapidly from 50, to 55 in 2004, and then over 60 after 2012 (Figure 4).

\section{Mortality trend of liver cancer by period}

Taking 1972 as the first period, every 5 years as the next increments, 9 more periods covered the following 45 years in order to analyze the mortality rate of each age group. The results show that the mortality rate of liver cancer in the age group $\geq 75$ years fluctuated in the range of $50-70$ per $10^{5}$ before the $1990 \mathrm{~s}$, and then gradually increased to more than $100 / 10^{5}$, and by 2013-2017, it had exceeded 200/105. At age groups of 55-64 and 65-74 the rates have swayed around the range of 100-150 per 105. A slight upward trend in the later period was found in the 55-64 age group, while a slight downward trend was seen at 45-54 age group. There were significant declining trends in all age groups under 54 years old, particularly at 35-44, 25-34, and 15-24 (Figure 5).

The analysis with the Joinpoint Regression Program showed that the mortality rate at age group $\geq 75$ years had a significant upwards trend in 1972-2017, with an AAPC of $+3.69 \%$; and at age group of $65-74$ years, AAPC was $+0.95 \%$. The younger the age, the more significant the trend for declining mortality from liver cancer: AAPCs at 55-64, 45-54, and 35-44 were -0.85\%, $-1.73 \%$ and $-3.58 \%$, respectively (Figure 6).

\section{Liver cancer mortality in the birth cohorts}

Birth cohort analysis demonstrated that the mortality of liver cancer in age groups of 15-19, 20-24, 25-29, 30-34, 35-34 and 40-44 displayed downward trends. At age groups of 45-49 and 50-54 the mortality began to show a downward trend in the later period of the birth cohort. In general, in the cohorts of "1953" and later births, clear cohort effects have been observed with respect to reduction of liver cancer mortality. However, in the cohort of before "1938", i.e., at age groups of 70-74, 75-79, 80 and over, the mortality rates showed rising trends (Figure 7). 
189

190

191

192

193

194

195

196

197

198

199

200

201

202

203

204

205

206

207

208

209

210

211

212

213

214

215

216

217

218

219

\section{Discussion}

The premise of cancer control is to understand the prevalence and trends of cancer. Therefore, long-run monitoring data on incidence or mortality are particularly of importance. Since the 1970s, Qidong City, Jiangsu Province has carried out a series of cancer research programs on prevention and treatment, such as retrospective survey of death, cancer registration reporting, studies of cancer etiology and prevention [6-8] that provide detailed information for the evaluation of long-term trends and comprehensive prevention effects of liver cancer mortality in Qidong, and in China as well.

Data over the past 60 years (Figure 1) show that the natural death rate in the Qidong population experienced an evolutive course from higher to lower, and then from lower back to higher, truly reflecting the dynamic characteristics of the local population due to substantial change of population structure $[8,16]$ and control of diseases: the slow decline of mortality rate (such as infectious diseases) in the general population in the early period, and the increase of mortality rate (such as chronic diseases) due to aging in the recent decades. That the trend of cancer mortality has increased likely reflects the synergetic effects of two factors: an increase of risk factors and the aging of the population. It is worth noting that the trend of liver cancer mortality before the beginning of this century was "synchronous" with the rate of increase of cancer; after 2008, liver cancer mortality was no longer elevated in concert with the increase of overall cancer mortality, but rather decreased. Other cancers such as lung cancer are now exerting dominance in Qidong.

Our data shows that liver cancer has been the primary form of cancer in Qidong since 1958. The observed crude mortality rate of liver cancer increased from $20.45 / 10^{5}$ in the 1950 's to about $50 / 10^{5}$ in the middle 1970 's, and reached to the highest level of more than $80 / 10^{5}$ at the turn of this century. Moreover, the proportion of liver cancer in all cancers was 35.49\% (4428/12476) in 1958-1971 and 30.53\% (31261/102390) in 1972-2017, meaning one in three cancer patients died of liver cancer. However, the proportion of liver cancer in total cancer death has declined substantively over the past decade. Table 1 shows that the proportion of liver cancer in total cancer deaths has declined to $22.52 \%(8004 / 35549)$ in the years $2008-2017$, and to $18.39 \%$ $(1925 / 10468)$ in just the last three years of analysis (2015-2017).

18 Based upon the data from the registration system, the overall mortality trend of liver cancer was evaluated. It can be seen that the percent change (PC) of the crude mortality of liver cancer 
220 during 1972-2017 was +17.78\%; but the PCs of ASRC and ASRW were $-61.25 \%$ and $-51.43 \%$, 221 showing a downward trend. Joinpoint Regression analysis illustrated that average annual percent 222 change (AAPC), in term of ASRW, displayed a clear declining trend, which was $-1.49 \%$ in men, $223-1.01 \%$ in women, and $-1.33 \%$ for both sexes (Figure 2). According to the multiple model of 224 Joinpoint Regression (Table 2), the AAPCs of men, women and the both were $-1.8 \%,-1.4 \%$ and $225-1.8 \%$, respectively, indicating that mortality from liver cancer in Qidong did show a significant 226 downward trend.

227 The similar trends have been found across China: the standardized mortality rate of liver 228 cancer, for instance, in Changning District, Shanghai during the years 1973-2013, was -2.1\% in 229 men and $-2.7 \%$ in women, respectively [17]. A recent study in China showed that the crude 230 mortality rate of liver cancer in China increased during 1997-2016, with an AAPC of $+0.5 \%$, but 231 the age-standardized rate was in decline [18]. Another report showed that the age-standardized 232 mortality rate of AAPC for liver cancer in China was $-0.5 \%$ in men, $-1.3 \%$ in women, and $-0.8 \%$ 233 in both sexes from 1990 to 2017 [19]. A South Korea report showed that the age-standardized 234 mortality rate of AAPC in 1983-2012 was $-1.55 \%$ in men and $-0.56 \%$ in women [20]. In a recent 235 Meta-analysis report [21] that included 31 population-based studies showed that the pooled APC 236 estimates for liver cancers was $+0.8 \%$, in which $+3.2 \%$ in the region of North

237 America/Europe/Australia, whereas $-1.7 \%$ in several Asian countries. These di $\square$ erent patterns 238 may reflect geographical variation or changes in the ratio of liver cancers attributable to various 239 risk factors.

240 The age-specific mortality rate from this 60-year data set showed that liver cancer 241 contributed the most hazard towards disease burden in the middle-aged and elderly residents. In 242 individuals over 35 years in Qidong, the mortality rate of liver cancer (over 110/105) has 243 exceeded the average level of the general population, and has been stable at the level of 110$244140 / 10^{5}$ for those over 45 years old. The cumulative rate and the cumulative risk of 0-74 years 245 old (which reflects the level of lifetime mortality) reached 5.15\% and 5.02\%, respectively, being 246 yet another metric of this cancer epidemic. In the 1970s and 1980s, it was found that the 247 proportion of liver cancer deaths in young adults was very high, in term of the truncated rate of 248 35-64 years: between $120 / 10^{5}$ and $140 / 10^{5}$ in the $1970 \mathrm{~s}-1980 \mathrm{~s}$, down to $100-110 / 10^{5}$ in 1990 2492005 , to less than $100 / 10^{5}$ in the last period, and even lower than 50/10 $0^{5}$ in the most recent 2 250 years. For the average death age of liver cancer, they were relatively young patients before the 
251 1990s, since then the average death age increased gradually from under 50 to exceed 65 years 252 old. These changes clearly show that the mortality of liver cancer in the Qidong youth and 253 middle-aged population has exhibited a rapid downward trend.

Furthermore, the change of liver cancer mortality in each age group by 5-year-period was

255

256

257

258

259

260

261

262

263

264

265

266

267

268

269

270

271

272

273

274

275

276

277

278

279

280

281

investigated (Figure 5). Gradual downward trends could be found in the age groups of 15-24, 2534, and 35-44 years old; but obvious up- or down-ward trends were not observed in the age groups of 45-54 and over, whilst fluctuated at high levels of mortality. However, the mortality of liver cancer in the age group over 75 years has continuously increased so far. Joinpoint regression analysis also shows that the AAPCs in those aged 35-44, 45-54 and 55-64 exhibited significantly decreasing trends, while in those aged 65-74, 75 and over exhibited significantly increasing trends (Figure 6). These results demonstrate that the high mortality rate for liver cancer in the elderly population, together with the increased proportion of the elderly population (aging), has had a great impact on the increasing crude mortality rate of liver cancer in this area. In the United States, the largest increases were observed in persons aged 55-59 years (AAPC, 8.9\%) and 60-64 years (AAPC, 6.4\%) between 2000 and 2012 [22].

The encouraging elements of this situation are, however, based upon the birth-cohort analysis. The cohort mortality rates in all age groups of 15-19, 20-24, 25-29, 30-34, 35-39 and 40-44 years old, i.e., for those born after the 1950s, have experienced weakened epidemic trends (Figure 7). This outcome has given a clear signal towards the prevention and control of liver cancer: the reduction of liver cancer mortality in the Qidong population has already been reflected in the young generation of this area; and, this downward trend is also being transmitted to the middle-aged cohort population. Thus, the key question is: what kind of causes (measures) led to the change (decline) of liver cancer mortality in the young and middle-aged people in Qidong?

Globally, there are many of risk factors contributing to liver cancer etiology, and different populations have disparate risk patterns [23]. Primary prevention precisely aimed at key risk factors is essential and perhaps the only realistic and sustainable approach [24]. During the past decades in the Qidong region, epidemiological and etiological research on liver cancer, control of risk factors, implementation of primary prevention (elimination of exposure to risk factors) and secondary prevention (early diagnosis and early treatment) have been the priority goals for liver cancer studies $[6,8,25,26]$. This effort has achieved positive results. The main measures that 
282 have been targeted to the major causes of liver cancer include: prevention of hepatitis B, 283 prevention of grain-mildew leading to aflatoxin contamination and detoxification, improvement 284 of drinking water source and secondary prevention. Which of these measures has made the most 285 direct and/or significant contributions to the decrease of liver cancer mortality in Qidong? It is 286 worth assessing the available information and evidence.

Hepatitis B virus (HBV) is known as perhaps the most important pathogenic factor of liver

288

289

290

291

292

293

294

295

296

297

298

299

300

301

302

303

304

305

306

307

308

309

310

311 cancer etiology. Experimental research on HBV, and control of hepatic diseases have been undertaken since the 1970s in Qidong [6,26-28]. Most important, hepatitis B vaccination in infants started in 1983: the newborns in some of townships would receive three doses of hepatitis $\mathrm{B}$ vaccine, but the limited coverage of this program led to only a small proportion of actual vaccinations in the newborns prior to 2002. Then, hepatitis B vaccination was included into the Expanded Program on Immunization (EPI) in China [29,30] which made it possible to vaccinate all newborns with full population (and financial) coverage in Qidong [28]. It does mean though, that as of the year 2017, most of the hepatitis B vaccine recipients have been under the age of 20 years, who in turn did not contribute to the real changes observed in the mortality curve. In other words, it is obvious that the curve on the right side of the "1983" birth cohort as in Figure 7 is not enough to affect the downtrend of mortality rate of liver cancer in the Qidong population. But, if one focuses on the period results in Figure 4 one would speculate that the decline curve in the age group of 15-24, for instance, is likely due to vaccination. Obviously, the cross-sectional results (Figure 5) obscure the real effects within the cohort results (Figure 7). An early report from Taiwan proffered a conclusion that the incidence of hepatocellular carcinoma in children has declined due to the hepatitis B vaccination [31]. But, we have noted that even in the figure of their paper, the major decline of incidence for the children of 6-14 years in fact occurred before 1984 when the vaccination had not yet been introduced. In a later paper [32] from a 20-year follow up, it was concluded that the prevention of hepatocellular carcinoma by this HBV vaccine extends from childhood to early adulthood. Accordingly, the decrease of liver cancer incidence/mortality in children/adolescence or young adults in Qidong or in Taiwan must be affected by the elimination or diminution of other risk factors (other than HBV) or other effective measures taken, simply because the changed panorama of liver cancer pattern in the general population happened before vaccination. 
The relationship between drinking water and liver cancer in Qidong has also attracted the interest of researchers [33,34]. However, it is not clear what kind of substance or pollution in the

314 water was related to the incidence (or mortality) of liver cancer. Possible factors include

315 cyanobacteria toxin (microcystins or cyanotoxins) [35-37], some chemical mutagens [38], or

316 even inorganic arsenic [39] in the water. There have been no reports to provide any strong

317 evidence in animal experiments as to causation of liver cancer, and not enough epidemiological

318 data in the population to establish the relationship between drinking water and the incidence or

319 mortality of liver cancer. It has been reported [409] that the distribution of cyanobacteria in the

320 United States is very extensive, but incidence rate of liver cancer has not been high for decades.

321 However, a recent report, based upon an ecological study in Ohio (USA), observed that a

322 population served by bloom-impacted surface waters had 14.2\% higher HCC incidence rates

323 than those served by non-bloom-impacted surface waters [41]. In a Canadian study, however, no

324 association with cyanobacterial toxin exposure in the geographic distribution of liver cancer was

325 observed, implying blue-green algae pollution may not play an important role in the etiology of

326 liver cancer in Canada [42]. Qidong has gradually changed the sources of drinking water since

327 the 1980s and vastly expanded the coverage of piped tap water since the beginning of this

328 century [43]. Yet the existing evidence related to a role of drinking water is not sufficient to

329 illuminate the inevitable relationship between the decrease of liver cancer mortality and the

330 change of drinking water source and causality in Qidong over the past decades.

331 There have been many reports on the relationship between aflatoxin and liver cancer,

332 showing that aflatoxin can be a critical etiological factor of liver cancer in some geographical

333 regions [44-46]. Corn can be easily contaminated by aflatoxin (produced by Aspergillus flavus)

334 and was a staple food of Qidong residents for a long time, especially in times of food shortages.

335 In the $1970 \mathrm{~s}$, the contamination rate of aflatoxin in corn (levels exceeding $20 \mathrm{ppb}$ ) ranged from

$3365.68-98.79 \%$ [6]. Animal experiments using corn harvested from Qidong fields exhibited definite

337 hepatocarcinogenic effects on rats and ducks in the 1970s [6]. Since then comprehensive

338 preventive measures to control aflatoxin contamination, so called "post-harvest management",

339 have been undertaken in Qidong [6,26]. In response to social and economic changes, from the

340 mid-1980s, Qidong residents (all age groups) completely changed their habit of eating corn to

341 rice (known to be much less contaminated by aflatoxin) [6,7,26]. These changes of habit and

342 other control measures have led to impressive results evidenced by exposure biomarkers detected 
343 in historical biobank blood samples: the median levels of aflatoxin-albumin adducts in Qidong 344 residents decreased significantly from $19.3 \mathrm{pg} / \mathrm{mg}$ in 1989 to 3.6 in $1995 \mathrm{pg} / \mathrm{mg}, 2.3 \mathrm{pg} / \mathrm{mg}$ in

$3451999,1.4 \mathrm{pg} / \mathrm{mg}$ in 2003, and undetected $(<0.5 \mathrm{pg} / \mathrm{mg})$ levels in 2009 and 2012 [16]. The

346 exposure level of aflatoxin in this decade has decreased to a level of $>1 / 40$ th of the level in the

347 1980s. To date, this provides the most and perhaps only convincing evidence for the causal link

348 (association) between the elimination of risk factors and the reduction of mortality of liver

349 cancer, especially as supported by the birth-cohort analysis that demonstrates about a 50\%

350 decrease of ASRW of liver cancer over the past decades. From Figure 5 and Figure 7, we also

351 noted that the trend of mortality at aged 75 and over was not decreasing but in fact increasing.

352 This outcome may reflect that the diminution of aflatoxin exposure in the late period of life was

353 too late to affect aging people or may reflect a "delayed toxicity" [46]. This interpretation is

354 plausible given the long latency period for the development of liver cancer.

355 There may be other risk factors contributing to liver cancer etiology in Qidong. Hepatitis C

356 virus, for example, is of most interest globally [24,47]. However, there has been no evidence to

357 show this virus was common in the general population, or in patients with liver cancer in Qidong

358 over the past 60 years. In our previous nested case-control study early this century, we found that

359 the prevalence of HCV infection was low (1.6\% in cases $v s .2 .1 \%$ in controls) and did not seem

360 to play a role in the etiology for liver cancer [48]. A 13.25 year follow-up study in Qidong also

361 indicated that only 6 of 119 liver cancer patients with positive HBV were coinfected with HCV,

362 contributing little to the risk of hepatocellular carcinoma [49]. Besides the major risk factors as

363 mentioned above, there may be other minor risk factors or the interaction effects of risk factors

364 from environment or from mutagens [36,48,50,51]. In recent times, diabetes mellitus (DM),

365 metabolic syndrome (MetS) and obesity or metabolic disease/obesity have been considered as a

366 growing problems for the development of liver cancer [52-54]. In a 2015 study from Jiangsu

367 province where Qidong is located, the prevalences of DM were 8.6\% in men and 8.4\% in women,

368 and 2.7-4.8\% at ages of 18-44 and 13.2\% at ages over 65 [55]. In a study of 325 patients with

369 liver cancer in our Qidong hospital [56], 31.38\% had type II DM, and those who were at age of

370 over $60 v s$. under 60 , the rates were $43.14 \%$ vs. $13.28 \%$, indicating a possible association

371 between DM and the risk of liver cancer in the elderly. This may also partially explain why the

372 birth cohort of age groups over 65 had increased mortality (Figure 7). However, in a Taiwan

373 study [57], it was concluded that DM, MetS and obesity were not associated with liver cancer 
374 development in hepatitis virus infected groups within an epidemic area. These factors need to be

375 further observed and studied. Hence, among these mentioned factors and or the effects on liver

376 cancer, either there was insufficient evidence or a synergistic effect with aflatoxin or HBV

377 synchronously. Furthermore, the population attributable risk (PAR) for developing liver cancer

378 in the general population was limited, so it was unlikely to affect the downward trend of liver 379 cancer mortality in Qidong.

380 Secondary prevention, which involves early diagnosis and early detection, could influence

381 liver cancer mortality. In the 1970s, a series of large-scale screening programs for early diagnosis

382 and treatment of liver cancer measuring serum alpha-fetoprotein (AFP) were carried out. A large

383 number of early liver cancer patients were detected and some good outcomes achieved [6].

384 However, the mortality rates of liver cancer in Qidong at that period fluctuated at a high level

385 (Figure 1, Table 1). In a 1980's liver cancer screening program in Qidong, it was found that

386 focused screening within a high-risk population could improve the detection levels of liver

387 cancer, with a short-term effect on the change of survival rate, but no effect on mortality in the

388 long term [58]. After 2007, periodical diagnostic screening using combined methods of AFP and

389 ultrasound examination monitoring were recommended. This practice has shown the effect of

390 screening on the early diagnosis and treatment, and may improve the outcome of liver cancer for

391 some [59]. However, the proportion of patients who received the early diagnosis relative to the

392 total number of patients in Qidong was still too small, and insufficient to affect mortality

393 outcomes in the general population. Unfortunately, in general, the now substantial decrease of

394 liver cancer mortality in Qidong cannot be attributed to a change in the detection rate or to

395 improvements in treatment, but rather to changes in the matrix of risk factors in the population.

\section{Conclusions}

397 The crude mortality rate of liver cancer in Qidong experienced a dynamic flux from low to

398 high, then sustained at high levels for decades, followed by a gradual decrease in recent years.

399 After excluding the influence of the "aging" of the Qidong population, it emerged that the

400 decrease of the standardized mortality rate of liver cancer in Qidong happened earlier than that of

401 the crude rate, and the decline has accelerated since the beginning of this century. Moreover, it

402 was first reflected in the newest generation, with a higher slope of decline in men who are at 3-

403 fold higher risk than women overall. In a comprehensive investigation of the risk factors that

404 may affect the downward trends in Qidong, the most significant effect appears to be the control 
405 of mildew in the staple food (corn), coupled with profound dietary changes effected by social 406 and economic mandates, to result in dramatic declines in the intake of aflatoxin. This change in 407 the exposure was documented directly with the use of analytically rigorous methods for 408 measures of biological markers in archived serum samples collected longitudinally within the 409 population. The beneficial effect of improving drinking water may not be excluded, but direct 410 positive evidence has not been obtained so far. The prevention of hepatic diseases, such as 411 hepatitis B, must not be ignored, since hepatitis B vaccination has shown effectiveness in 412 prevention of liver diseases in children [31,60], but has not yet been reflected in the prevention 413 of liver cancer in the adult populations. For certain, the present evidence regarding HBV 414 vaccination is not enough to explain or contribute to the current declining trend of liver cancer 415 mortality in Qidong. The change (reduction) of liver cancer mortality in the past six decades has 416 clearly implied that the efforts in Qidong have shown the promise of the control of liver cancer. 417 Through unremitting efforts in a landscape of social, economic, environmental and medical 418 change, liver cancer in Qidong is no longer the number one cause of cancer mortailty, having 419 been overtaken by lung cancer in the past decade $[8,61]$. The etiological mechanisms need to be explored further, yet the rationale and appropriateness of the measures taken in Qidong area have been proven, and has helped us to better understand the etiology of liver cancer in this region.

422 Six decades of monitoring the state of liver cancer mortality in Qidong coupled with rigorous, 423 longitudinal monitoring of aflatoxin biomarkers, has provided a working example that reducing 424 aflatoxin contamination can be achieved by interventions at the population level; in our case, has 425 also provided vigorous evidence that controlling aflatoxin may help reduce substantively the 426 burden of morbidity and mortality of liver cancer.

\section{Acknowledgements}

428 We thank our colleagues at the QDLCI, the Qidong People's Hospital, the Shanghai 429 Cancer Institute and Johns Hopkins University who have assisted in our studies. We thank the 430 leadership of the Qidong City government for fostering our collaborations, and most importantly, 431 thank the many residents of Qidong as well as the local doctors for their dedicated participation 432 in these studies. They have been the enablers to probe the etiology and prevention of liver 433 cancer. 
436 1. Bray F, Ferlay J, Soerjomataram I, Siegel RL, Torre LA, Jemal A. Global cancer statistics

437

438

439

440

441

442

443

444

445

446

447

448

449

450

451

452

453

454

455

456

457

458

459

460

461

462

463

464

465

466

467

468

469

470 2018: GLOBOCAN estimates of incidence and mortality worldwide for 36 cancers in 185 countries. CA Cancer J Clin. 2018; 68(6): 394-424. doi:10.3322/caac.21492.

2. Liu Z, Mao X, Jiang Y, Cai N, Jin L, Zhang T, Chen X. Changing trends in the disease burden of primary liver cancer caused by specific etiologies in China. Cancer Med. 2019; 8(12):5787-99. doi:10.1002/cam4.2477.

3. Allemani C, Matsuda T, Di Carlo V, Harewood R, Matz M, Nikšić M, Bonaventure A, Valkov M, Johnson CJ, Estève J, Ogunbiyi OJ, Azevedo E Silva G, Chen WQ, Eser S, Engholm G, Stiller CA, Monnereau A, Woods RR, Visser O, Lim GH, Aitken J, Weir HK, Coleman MP; CONCORD Working Group. Global surveillance of trends in cancer survival 2000-14 (CONCORD-3): analysis of individual records for 37513025 patients diagnosed with one of 18 cancers from 322 population-based registries in 71 countries. Lancet. 2018; 391(10125):1023-75. doi:10.1016/S0140-6736(17)33326-3.

4. Zeng H, Chen W, Zheng R, Zhang SW, Ji J, Zou X, Xia C, Sun K, Yang Z, Li H, Wang N, Han R, Liu S, Li H, Mu H, He Y, Xu Y, Fu Z, Zhou Y, Jiang J, Yang Y, Chen J, Wei K, Fan D, Wang J, Fu F, Zhao D, Song G, Chen J, Jiang C, Zhou X, Gu X, Jin F, Li Q, Li Y, Wu T, Yan C, Dong J, Hua Z, Baade P, Bray F, Jemal A, Yu XQ, He J. Changing cancer survival in China during 2003-15: a pooled analysis of 17 population-based cancer registries. Lancet Glob Health. 2018; 6(5): e555-e567. doi:10.1016/S2214-109X(18)30127-X.

5. Global Burden of Disease Cancer Collaboration, Fitzmaurice C, Akinyemiju TF, Al Lami FH, Alam T, Alizadeh-Navaei R, Allen C, Alsharif U, Alvis-Guzman N, Amini E, Anderson BO, Aremu O, Artaman A, Asgedom SW, Assadi R, Atey TM, Avila-Burgos L, Awasthi A, Ba Saleem HO, Barac A, Bennett JR, Bensenor IM, Bhakta N, Brenner H, Cahuana-Hurtado L, Castañeda-Orjuela CA, Catalá-López F, Choi JJ, Christopher DJ, Chung SC, Curado MP, Dandona L, Dandona R, das Neves J, Dey S, Dharmaratne SD, Doku DT, Driscoll TR, Dubey M, Ebrahimi H, Edessa D, El-Khatib Z, Endries AY, Fischer F, Force LM, Foreman KJ, Gebrehiwot SW, Gopalani SV, Grosso G, Gupta R, Gyawali B, Hamadeh RR, Hamidi S, Harvey J, Hassen HY, Hay RJ, Hay SI, Heibati B, Hiluf MK, Horita N, Hosgood HD, Ilesanmi OS, Innos K, Islami F, Jakovljevic MB, Johnson SC, Jonas JB, Kasaeian A, Kassa TD, Khader YS, Khan EA, Khan G, Khang YH, Khosravi MH, Khubchandani J, Kopec JA, Kumar GA, Kutz M, Lad DP, Lafranconi A, Lan Q, Legesse Y, Leigh J, Linn S, Lunevicius R, Majeed A, Malekzadeh R, Malta DC, Mantovani LG, McMahon BJ, Meier T, Melaku YA, Melku M, Memiah P, Mendoza W, Meretoja TJ, Mezgebe HB, Miller TR, Mohammed S, Mokdad AH, Moosazadeh M, Moraga P, Mousavi SM, Nangia V, Nguyen CT, Nong VM, Ogbo FA, Olagunju AT, Pa M, Park EK, Patel T, Pereira DM, Pishgar F, Postma MJ, 
471

472

473

474

475

476

477

478

479

480

481

482

483

484

485

486

487

488

489

490

491

492

493

494

495

496

497

498

499

500

501

502

503

504

Pourmalek F, Qorbani M, Rafay A, Rawaf S, Rawaf DL, Roshandel G, Safiri S, Salimzadeh H, Sanabria JR, Santric Milicevic MM, Sartorius B, Satpathy M, Sepanlou SG, Shackelford KA, Shaikh MA, Sharif-Alhoseini M, She J, Shin MJ, Shiue I, Shrime MG, Sinke AH, Sisay M, Sligar A, Sufiyan MB, Sykes BL, Tabarés-Seisdedos R, Tessema GA, Topor-Madry R, Tran TT, Tran BX, Ukwaja KN, Vlassov VV, Vollset SE, Weiderpass E, Williams HC, Yimer NB, Yonemoto N, Younis MZ, Murray CJL, Naghavi M. Global, regional, and national cancer incidence, mortality, years of life lost, years lived with disability, and disability-adjusted life-years for 29 cancer groups, 1990 to 2016: a systematic analysis for the global burden of disease study. JAMA Oncol. 2018; 4(11): 1553-68. doi:10.1001/jamaoncol.2018.2706.

6. Zhu YR, Chen JG, Huang XY. Hepatocellular carcinoma in Qidong county. In: Tang ZY, Wu MC, Xia SS, eds. Primary Liver Cancer. Beijing: China Academic Publishers, SpringerVerlag, 1980: 204-22.

7. Chen JG, Zhu J, Wang GR, Groopman JD, Kensler TW. Qidong: a crucible for studies on liver cancer etiology and prevention. Cancer Biol Med. 2019; 16(1): 24-37. doi:10.20892/j.issn.2095-3941.2018.0394.

8. Chen JG, ed. Cancer in Qidong, 1972-2011. Beijing: Military Medical Science Press, 2013: $1-346$.

9. Parkin DM, Whelan SL, Ferlay J, Raymond L, Young J, eds. Cancer Incidence in Five Continents, Vol VII, IARC Sci Pub No. 143, Lyon: IARC, 1997: 1-1240.

10. Bray F, Colombet M, Mery L, Piñeros M, Znaor A, Zanetti R, eds. Cancer Incidence in Five Continents, Vol. XI (electronic version). Lyon: International Agency for Research on Cancer. Available from: http://ci5.iarc.fr, (21 March 2020).

11. He J, Chen WQ, eds. 2015 Chinese Cancer Registry Annual Report. Beijing: Tsinghua University Press, 2017:1-446.

12. He J, Chen WQ, eds. 2016 Chinese Cancer Registry Annual Report. Beijing: Tsinghua University Press, 2017, 2017:1-550.

13. Chen JG, Zhu J, Parkin DM, Zhang YH, Lu JH, Zhu YR, Chen TY. Trends in the incidence of cancer in Qidong, China, 1978-2002. Int J Cancer. 2006; 119(6): 1447-54.

14. National Cancer Institute. Joinpoint Regression Program, Version 4.7.0.0 (February 2019). Bethesda,
MD:
National
Cancer
Institute.
Available
at: http://surveillance.cancer.gov/joinpoint/. Accessed March 23, 2020.

15. Clegg LX, Hankey BF, Tiwari R, Feuer EJ, Edwards BK. Estimating average annual per cent change in trend analysis. Stat Med. 2009; 28:3670-82. 
505

506

507

508

509

510

511

512

513

514

515

516

517

518

519

520

521

522

523

524

525

526

527

528

529

530

531

532

533

534

535

536

537

538

16. Chen JG, Egner PA, Ng D, Jacobson, LP, Munoz A, Zhu YR, Qian GS, Wu F, Yuan JM, Groopman JD, Kensler TW. Reduced aflatoxin exposure presages decline in liver cancer mortality in an endemic region of China. Cancer Prev Res (Phila). 2013, 6(10): 1038-045. doi:10.1158/1940-6207.CAPR-13-0168.

17. Ji XW, Jiang Y, Wu H, Zhou P, Tan YT, Li HL, Zhang L, Zhao WS, Xia QH, Bray F, Xiang YB. Long-term liver cancer incidence and mortality trends in the Changning District of Shanghai, China. J Dig Dis. 2020; 21(4):230-6. doi:10.1111/1751-2980.12855.

18. Ding C, Fu X, Zhou Y, Liu X, Wu J, Huang C, Deng M, Li Y, Li L, Yang S. Disease burden of liver cancer in China from 1997 to 2016: an observational study based on the Global Burden of Diseases. BMJ Open. 2019; 9(4):e025613. Published 2019 Apr 23. doi:10.1136/bmjopen-2018-025613.

19. Wang F, Mubarik S, Zhang Y, Wang L, Wang YF, Yu CH, Li H. Long-term trends of liver cancer incidence and mortality in China 1990-2017: a Joinpoint and Age-Period-Cohort analysis. Int J Environ Res Public Health. 2019; 16(16): 2878. doi:10.3390/ijerph16162878.

20. Lim D, Ha M, Song I. Trends in major cancer mortality in Korea, 1983-2012, with a joinpoint analysis. Cancer Epidemiol. 2015; 39(6):939-946. doi:10.1016/j.canep.2015.10.023.

21. Dasgupta P, Henshaw C, Youlden DR, Clark PJ, Aitken JF, Baade PD. Global trends in incidence rates of primary adult liver cancers: A systematic review and Meta-analysis. Front Oncol. 2020; 10:171. Published 2020 Feb 28. doi:10.3389/fonc.2020.00171.

22. White DL, Thrift AP, Kanwal F, Davila J, El-Serag HB. Incidence of Hepatocellular Carcinoma in All 50 United States, From 2000 Through 2012. Gastroenterology. 2017;152(4):812-20.e5. doi:10.1053/j.gastro.2016.11.020.

23. Pham C, Fong TL, Zhang J, Liu L. Striking Racial/Ethnic Disparities in Liver Cancer Incidence Rates and Temporal Trends in California, 1988-2012. J Natl Cancer Inst. 2018;110(11):1259-69. doi:10.1093/jnci/djy051.

24. Yang JD, Hainaut P, Gores GJ, Amadou A, Plymoth A, Roberts LR. A global view of hepatocellular carcinoma: trends, risk, prevention and management. Nat Rev Gastroenterol Hepatol. 2019; 16(10):589-604. doi:10.1038/s41575-019-0186-y.

25. Chen JG, Zhu J, Zhang YH, Zhu YR, Lu JH. Evaluation of Secular Trend of Liver Cancer Incidence in Qidong, Jiangsu Province, 1973-2002. Nat Med J Chin (Zhonghua Yi Xue Za Zhi). 2005; 85(43):3052-6.

26. Chen JG, Chen TY, Zhu YR, Zhu J, Lu JH, Wang JB, Sun Y, Zhang YH, Wu Y, Chen YS, $\mathrm{Lu}$ LL. Research on strategies for prevention and control of liver cancer and the efficacy of 
539

540

541

542

543

544

545

546

547

548

549

550

551

552

553

554

555

556

557

558

559

560

561

562

563

564

565

566

567

568

569

570

571

572

field interventions in Qidong. Tumor (Zhongliu). 2014; 34(11): 1052-7.

27. Chen JG, Lu JH, Zhu YR, Zhu J, Zhang YH. A thirty-one year prospective follow-up program on the HBsAg carrier state and primary liver cancer in Qidong, China. Chin J Epidemiology (Zhonghua Liu Xing Bing Xue Za Zhi). 2010; 31(7):721-6.

28. Sun Z, Ming L, Zhu X, Lu J. Prevention and control of hepatitis B in China. J Med Virol. 2002; 67(3):447-50.

29. Hutton DW, So SK, Brandeau ML. Cost-effectiveness of nationwide hepatitis B catch-up vaccination among children and adolescents in China. Hepatology. 2010; 51(2):405-14. doi:10.1002/hep.23310.

30. Luo Z, Li L, Ruan B. Impact of the implementation of a vaccination strategy on hepatitis B virus infections in China over a 20-year period. Int J Infect Dis. 2012; 16(2):e82-8. doi:10.1016/j.ijid.2011.10.009.

31. Chang MH, Chen CJ, Lai MS, Hsu HM, Wu TC, Kong MS, Liang DC, Shau WY, Chen DS. Universal hepatitis B vaccination in Taiwan and the incidence of hepatocellular carcinoma in children. Taiwan Childhood Hepatoma Study Group. N Engl J Med. 1997; 336(26):1855-9.

32. Chang MH, You SL, Chen CJ, Liu CJ, Lee CM, Lin SM, Chu HC, Wu TC, Yang SS, Kuo HS, Chen DS, Taiwan Hepatoma Study Group. Decreased incidence of hepatocellular carcinoma in hepatitis B vaccinees: a 20-year follow-up study. J Natl Cancer Inst. 2009; 101(19):1348-55. doi:10.1093/jnci/djp288.

33. Su DL. Drinking water and liver cell cancer: an epidemiology approach to the etiology of this disease in China. Chin . 1979; 92: 748-56.

34. Yu SZ. Primary prevention of hepatocellular carcinoma. J Gastroenterol Hepatol. 1995; 10(6): 674-82. doi:10.1111/j.1440-1746.1995.tb01370.x.

35. Yu S, Zhao N, Zi X. The relationship between cyanotoxin (microcystin, MC) in pond-ditch water and primary liver cancer in China. Chin J Oncol (Zhonghua Zhong Liu Za Zhi). 2001; 23(2):96-9.

36. Lian M, Liu Y, Yu SZ, Qian GS, Wan SG, Dixon KR. Hepatitis B virus x gene and cyanobacterial toxins promote aflatoxin B1-induced hepatotumorigenesis in mice. World $\mathrm{J}$ Gastroenterol. 2006; 12(19): 3065-72. doi:10.3748/wjg.v12.i19.3065.

37. Labine M, Minuk GY. Long-term, low-dose exposure to microcystin toxin does not increase the risk of liver tumor development or growth in mice. Hepatol Res. 2015; 45(6):683-692. doi:10.1111/hepr.12394.

38. Ruan CC, Chen YH, Zhang ZQ. Drinking water and liver cancer. World J Gastroenterol. 
573

574

575

576

577

578

579

580

581

582

583

584

585

586

587

588

589

590

591

592

593

594

595

596

597

598

599

600

601

602

603

604

605

606

1997; 3(1):47-9. doi:10.3748/wjg.v3.i1.47.

39. Wang W, Cheng S, Zhang D. Association of inorganic arsenic exposure with liver cancer mortality: A meta-analysis. Environ Res. 2014; 135:120-5. doi:10.1016/j.envres.2014.08.034.

40. Zhang F, Lee J, Liang S, Shum CK. Cyanobacteria blooms and non-alcoholic liver disease: evidence from a county level ecological study in the United States. Environ Health. 2015; 14:41. doi:10.1186/s12940-015-0026-7.

41. Gorham T, Dowling Root E, Jia Y, Shum CK, Lee J. Relationship between cyanobacterial bloom impacted drinking water sources and hepatocellular carcinoma incidence rates. Harmful Algae. 2020; 95:101801. doi:10.1016/j.hal.2020.101801.

42. Labine MA, Green C, Mak G, Xu L, Nowatzki J, Griffith J, Minuk GY. The geographic distribution of liver cancer in Canada does not associate with cyanobacterial toxin exposure. Int J Environ Res Public Health. 2015; 12(12): 15143-53.

43. Chen JG. Advances in the etiology and prevention for primary liver cancer. Chin J Prev Treat (Zhonghua Zhong Liu Fang Zhi Za Zhi). 2003; 10(11): 1121-5.

44. IARC. IARC Monographs on the Evaluation of Carcinogenic Risks to Humans, Vol. 56. IARC: Lyon, 1993: 245-395.

45. Kensler TW, Roebuck BD, Wogan GN, Groopman JD. Aflatoxin: a 50-year odyssey of mechanistic and translational toxicology. Toxicol Sci. 2011; 120 (Suppl 1): S28-48.

46. Benkerroum N. Retrospective and prospective look at aflatoxin research and development from a practical standpoint. Int J Environ Res Public Health. 2019; 16(19):3633. doi:10.3390/ijerph16193633.

47. Maucort-Boulch D, de Martel C, Franceschi S, Plummer M. Fraction and incidence of liver cancer attributable to hepatitis $\mathrm{B}$ and $\mathrm{C}$ viruses worldwide. Int $\mathrm{J}$ Cancer. 2018; 142(12):2471-7. doi:10.1002/ijc.31280.

48. Szymañska K, Chen JG, Cui Y, Gong YY, Turner PC, Villar S, Wild CP, Parkin DM, Hainaut P. TP53 R249S mutations, exposure to aflatoxin, and occurrence of hepatocellular carcinoma in a cohort of chronic hepatitis B virus carriers from Qidong, China. Cancer Epidemiol Biomarkers Prev. 2009; 18(5):1638-43. doi:10.1158/1055-9965.EPI-08-1102.

49. Ming L, Thorgeirsson SS, Gail MH, Lu PX, Harris CC, Wang N, Shao Y, Wu Z, Liu G, Wang X, Sun Z. Dominant role of hepatitis B virus and cofactor role of aflatoxin in hepatocarcinogenesis in Qidong, China. Hepatology. 2002; 36(5):1214-20. doi:10.1053/jhep.2002.36366.

50. Kensler TW, Qian GS, Chen JG, Groopman JD. Translational strategies for cancer prevention in liver. Nat Rev Cancer. 2003;3(5):321-9. doi:10.1038/nrc1076. 
607 51. Zhang W, He H, Zang M, Wu Q, Zhao H, Lu LL, Ma P, Zheng H, Wang N, Zhang Y, He S, 608 Chen X, Wu Z, Wang X, Cai J, Liu Z, Sun Z, Zeng YX, Qu C, Jiao Y. Genetic features of

609

610

611

612

613

614

615

616

617

618

619

620

621

622

623

624

625

626

627

628

629

630

631

632

633

634

635

636

637

638

639

640 aflatoxin-associated hepatocellular carcinoma. Gastroenterology. 2017; 153(1):249-62.e2. doi:10.1053/j.gastro.2017.03.024.

52. Davila JA, Morgan RO, Shaib Y, McGlynn KA, El-Serag HB. Diabetes increases the risk of hepatocellular carcinoma in the United States: a population-based control study. Gut 2005; 54: $533 \mathrm{e} 9$.

53. Kim DY, Han KH. Epidemiology and surveillance of hepatocellular carcinoma. Liver Cancer. 2012; 1(1): 2-14. doi:10.1159/000339016.

54. Li X, Xu H, Gao P. Diabetes Mellitus is a Risk Factor for Hepatocellular Carcinoma in Patients with Chronic Hepatitis B Virus Infection in China. Med Sci Monit. 2018; 24:6729734. Published 2018 Sep 24. doi:10.12659/MSM.911702.

55. Tao R, Zhou JY, Su J, Zhang YQ, Li SR, Yang J, Zhou J, Zhang Y, Wu M, Tao R. Relationship between dyslipidemia and diabetes mellitus among adult residents in Jiangsu province. Chin J Public Health. 2015; 31(5): 562.

56. Song H, Mo B, Xue X, Yang Y, Huang X. Analysis on related factors of primary liver cancer complicated with type 2 diabetes mellitus. Oncol Progress. 2018; 16(14):1801-3.

57. Chen CT, Chen JY, Wang JH, Chang KC, Tseng PL, Kee KM, Chen PF, Tsai LS, Chen SC, Lin SC, Lu SN. Diabetes mellitus, metabolic syndrome and obesity are not significant risk factors for hepatocellular carcinoma in an HBV- and HCV-endemic area of Southern Taiwan. Kaohsiung J Med Sci. 2013; 29(8):451-9. doi:10.1016/j.kjms.2012.12.006.

58. Chen JG, Parkin DM, Chen QG, Lu JH, Shen QJ, Zhang BC, Zhu YR. Screening for liver cancer: results of a randomised controlled trial in Qidong, China. J Med Screen. 2003; 10(4):204-9. doi:10.1258/096914103771773320.

59. Chen JG, Zhang YH, Zhu J, Lu JH, Wang JB, Sun Y, Xue XF, Lu LL, Chen YS, Wu Y, Jiang XP, Ding LL, Zhang QN, Zhu YR. Early diagnosis and early treatment for liver cancer in Qidong: Survival of patients and effectiveness of screening. Chin J Oncol (Zhonghua Zhong Liu Za Zhi). 2017; 39(12): 946-51. doi:10.3760/cma.j.issn.0253-3766.2017.12.013.

60. Qu C, Chen T, Fan C, Zhan Q, Wang Y, Lu J, Lu LL, Ni Z, Huang F, Yao H, Zhu J, Fan J, Zhu Y, Wu Z, Liu G, Gao W, Zang M, Wang D, Dai M, Hsia CC, Zhang Y, Sun Z. Efficacy of neonatal HBV vaccination on liver cancer and other liver diseases over 30-year follow-up of the Qidong hepatitis B intervention study: a cluster randomized controlled trial. PLoS Med. 2014; 11(12):e1001774. doi:10.1371/journal.pmed.1001774.

61. Chen JG, Kensler TW. Changing rates for liver and lung cancers in Qidong, China. Chem 
641 Res Toxicol. 2014; 27(1):3-6. doi:10.1021/tx400313j.

642 
643

\section{Figure Legends}

645 FIGURE 1 Natural death rate, mortality rates of cancer and of liver cancer in Qidong, 1958-2017

646 FIGURE 2 AAPC models of WASR by sex for liver cancer mortality in Qidong, 1972-2017

647 FIGURE 3 The APC of liver cancer mortality in Qidong, 1972-2017

648 FIGURE 4 The average ages of patients with liver cancer in Qidong, 1972-2017

649 FIGURE 5 Age-specific mortality rates of liver cancer by period in Qidong, 1972-2017

650 FIGURE 6 AAPCs of mortality rates of liver cancer by age group in Qidong, 1972-2017

651 FIGURE 7 Birth-cohort mortality rates of liver cancer in Qidong, 1972-2017 
Table $\mathbf{1}$ (on next page)

Crudemortality, truncated rate and cumulative rate of liver cancer in Qidong,1972-2017 
1 Crude mortality, truncated rate and cumulative rate of liver cancer in Qidong, 1972-2017

\begin{tabular}{|c|c|c|c|c|c|c|c|}
\hline Year & $\begin{array}{l}\text { No. of cancer } \\
\text { death }\end{array}$ & $\begin{array}{l}\text { No. of liver } \\
\text { cancer death }\end{array}$ & $\begin{array}{c}\begin{array}{c}\text { Of total } \\
\text { cancer }\end{array} \\
(\%)\end{array}$ & $\begin{array}{c}\text { Liver cancer } \\
\text { mortality rate } \\
\left(\text { per } 10^{5}\right)\end{array}$ & $\begin{array}{c}\text { Truncated rate of } \\
35-64 \\
\left(\text { per } 10^{5}\right)\end{array}$ & $\begin{array}{c}\text { Cumulative } \\
\text { rate of 0-74 } \\
(\%)\end{array}$ & $\begin{array}{c}\begin{array}{c}\text { Cumulative } \\
\text { risk }\end{array} \\
(\%)\end{array}$ \\
\hline 1958 & 438 & 158 & 36.07 & 20.45 & NA & NA & NA \\
\hline 1959 & 577 & 210 & 36.40 & 26.79 & & & \\
\hline 1960 & 583 & 213 & 36.54 & 26.79 & & & \\
\hline 1961 & 472 & 171 & 36.23 & 21.35 & & & \\
\hline 1962 & 678 & 226 & 33.33 & 27.49 & & & \\
\hline 1963 & 689 & 237 & 34.40 & 27.74 & & & \\
\hline 1964 & 910 & 295 & 32.42 & 33.51 & & & \\
\hline 1965 & 985 & 333 & 33.81 & 36.89 & & & \\
\hline 1966 & 1062 & 358 & 33.71 & 38.77 & & & \\
\hline 1967 & 999 & 322 & 32.23 & 34.13 & & & \\
\hline 1968 & 1183 & 444 & 37.53 & 46.05 & & & \\
\hline 1969 & 1236 & 457 & 36.97 & 46.33 & & & \\
\hline 1970 & 1287 & 502 & 39.01 & 49.80 & & & \\
\hline 1971 & 1377 & 502 & 36.46 & 49.02 & & & \\
\hline 1972 & 1113 & 507 & 45.55 & 49.04 & 138.43 & 5.95 & 5.78 \\
\hline 1973 & 1112 & 469 & 42.18 & 44.97 & 127.22 & 5.40 & 5.26 \\
\hline 1974 & 1309 & 536 & 40.95 & 50.92 & 143.02 & 6.02 & 5.84 \\
\hline 1975 & 1533 & 560 & 36.53 & 52.74 & 148.67 & 6.21 & 6.02 \\
\hline 1976 & 1419 & 524 & 36.93 & 48.92 & 136.96 & 5.81 & 5.65 \\
\hline 1977 & 1468 & 529 & 36.04 & 49.00 & 140.24 & 5.68 & 5.52 \\
\hline 1978 & 1523 & 555 & 36.44 & 51.07 & 143.3 & 5.88 & 5.71 \\
\hline 1979 & 1557 & 555 & 35.65 & 50.84 & 134.29 & 5.55 & 5.40 \\
\hline 1980 & 1517 & 529 & 34.87 & 48.30 & 122.15 & 5.26 & 5.13 \\
\hline 1981 & 1530 & 510 & 33.33 & 46.38 & 119.84 & 4.99 & 4.86 \\
\hline 1982 & 1561 & 528 & 33.82 & 47.72 & 117.56 & 5.14 & 5.01 \\
\hline 1983 & 1615 & 603 & 37.34 & 54.18 & 127.46 & 5.44 & 5.30 \\
\hline 1984 & 1712 & 643 & 37.56 & 57.56 & 137.02 & 5.82 & 5.65 \\
\hline 1985 & 1752 & 634 & 36.19 & 56.60 & 131.84 & 5.85 & 5.68 \\
\hline 1986 & 1731 & 599 & 34.60 & 53.32 & 121.74 & 5.05 & 4.93 \\
\hline 1987 & 1680 & 607 & 36.13 & 53.75 & 125.13 & 5.18 & 5.05 \\
\hline
\end{tabular}




\begin{tabular}{|c|c|c|c|c|c|c|c|}
\hline 1988 & 1718 & 569 & 33.12 & 50.02 & 113.80 & 4.63 & 4.53 \\
\hline 1989 & 1740 & 536 & 30.80 & 46.77 & 100.11 & 4.16 & 4.07 \\
\hline 1990 & 1973 & 619 & 31.37 & 53.62 & 115.51 & 4.75 & 4.64 \\
\hline 1991 & 1963 & 622 & 31.69 & 53.59 & 110.56 & 4.69 & 4.58 \\
\hline 1992 & 1976 & 599 & 30.31 & 51.51 & 111.16 & 4.46 & 4.36 \\
\hline 1993 & 2034 & 680 & 33.43 & 58.43 & 116.94 & 4.91 & 4.79 \\
\hline 1994 & 2182 & 792 & 36.30 & 68.02 & 127.76 & 5.81 & 5.64 \\
\hline 1995 & 2313 & 804 & 34.76 & 69.07 & 127.65 & 5.46 & 5.31 \\
\hline 1996 & 2231 & 794 & 35.59 & 68.13 & 118.33 & 5.18 & 5.05 \\
\hline 1997 & 2064 & 802 & 38.86 & 68.71 & 114.69 & 5.32 & 5.18 \\
\hline 1998 & 2269 & 803 & 35.39 & 68.83 & 111.38 & 5.09 & 4.96 \\
\hline 1999 & 2266 & 797 & 35.17 & 68.51 & 118.64 & 5.04 & 4.91 \\
\hline 2000 & 2407 & 810 & 33.65 & 69.73 & 114.43 & 5.05 & 4.92 \\
\hline 2001 & 2347 & 853 & 36.34 & 73.58 & 115.23 & 5.04 & 4.92 \\
\hline 2002 & 2399 & 863 & 35.97 & 74.79 & 115.67 & 5.05 & 4.93 \\
\hline 2003 & 2456 & 809 & 32.94 & 70.50 & 104.53 & 4.67 & 4.57 \\
\hline 2004 & 2656 & 913 & 34.38 & 80.16 & 110.07 & 5.43 & 5.29 \\
\hline 2005 & 2897 & 863 & 29.79 & 76.28 & 102.88 & 4.93 & 4.81 \\
\hline 2006 & 2818 & 841 & 29.84 & 74.65 & 96.44 & 4.89 & 4.77 \\
\hline 2007 & 2853 & 802 & 28.11 & 71.52 & 91.19 & 4.24 & 4.15 \\
\hline 2008 & 3230 & 885 & 27.40 & 79.28 & 94.67 & 4.85 & 4.73 \\
\hline 2009 & 3043 & 798 & 26.22 & 71.57 & 80.65 & 4.26 & 4.17 \\
\hline 2010 & 3163 & 751 & 23.74 & 67.16 & 80.29 & 3.70 & 3.64 \\
\hline 2011 & 3324 & 746 & 22.44 & 66.47 & 75.38 & 3.81 & 3.74 \\
\hline 2012 & 3127 & 745 & 23.82 & 66.28 & 73.05 & 3.84 & 3.77 \\
\hline 2013 & 3199 & 703 & 21.98 & 62.56 & 63.85 & 3.51 & 3.44 \\
\hline 2014 & 3142 & 649 & 20.66 & 57.77 & 55.09 & 3.02 & 2.98 \\
\hline 2015 & 3451 & 686 & 19.88 & 61.15 & 58.70 & 3.41 & 3.36 \\
\hline 2016 & 3494 & 651 & 18.63 & 58.12 & 49.91 & 3.09 & 3.04 \\
\hline 2017 & 3523 & 588 & 16.69 & 52.61 & 43.92 & 2.84 & 2.80 \\
\hline Total* & 102390 & 31261 & 30.53 & 60.48 & 104.06 & 4.79 & 4.68 \\
\hline
\end{tabular}


Table 2 (on next page)

The APC and AAPC of liver cancer mortality bymultiple models simultaneously in Qidong, 1972-2017 
1 The APC and AAPC of liver cancer mortality by multiple models simultaneously in Qidong, 1972-2017

\begin{tabular}{|c|c|c|c|c|c|c|}
\hline Cohort & $\begin{array}{c}\text { Trend } \\
\text { (Segment) }\end{array}$ & Period & APC & $95 \% \mathrm{CI}$ & $\begin{array}{l}\text { Test Statistic } \\
\text { (t) }\end{array}$ & Prob $>|t|$ \\
\hline \multicolumn{7}{|l|}{$A P C:$} \\
\hline \multirow[t]{4}{*}{ Both sexes } & 1 & 1972-1992 & $-1.4^{*}$ & -1.8 to -0.9 & -6.1 & 0.00 \\
\hline & 2 & 1992-1995 & 4.5 & -9.9 to 21.2 & 0.6 & 0.50 \\
\hline & 3 & $1995-2006$ & $-1.4^{*}$ & -2.5 to -0.3 & -2.7 & 0.00 \\
\hline & 4 & 2006-2017 & $-4.7^{*}$ & -5.7 to -3.7 & -9.3 & 0.00 \\
\hline \multirow[t]{2}{*}{ Male } & 1 & $1972-2005$ & $-0.8^{*}$ & -1.1 to -0.6 & -7.0 & 0.00 \\
\hline & 2 & $2005-2017$ & $-4.5^{*}$ & -5.6 to -3.4 & -8.4 & 0.00 \\
\hline \multirow[t]{5}{*}{ Femal } & 1 & $1972-1986$ & -0.4 & -1.7 to 0.9 & -0.7 & 0.50 \\
\hline & 2 & 1986-1989 & -11.5 & -33 to 16.9 & -0.9 & 0.40 \\
\hline & 3 & 1989-1994 & 7.7 & -1.1 to 17.2 & 1.8 & 0.10 \\
\hline & 4 & 1994-2008 & -1.1 & -2.3 to 0.0 & -2.0 & 0.10 \\
\hline & 5 & 2008-2017 & $-4.7^{*}$ & -6.8 to -2.6 & -4.5 & 0.00 \\
\hline \multicolumn{7}{|l|}{ AAPC: } \\
\hline \multirow[t]{2}{*}{ Both sexes } & \multicolumn{2}{|c|}{ All period 1972-2017 } & $-1.3^{*}$ & -1.6 to -1.1 & -10.2 & 0.00 \\
\hline & \multicolumn{2}{|l|}{3 Joinpoints } & $-1.8^{*}$ & -2.8 to -0.8 & -3.5 & 0.00 \\
\hline \multirow[t]{2}{*}{ Male } & \multicolumn{2}{|c|}{ All period $1972-2017$} & $-1.5^{*}$ & -1.7 to -1.2 & -11.7 & 0.00 \\
\hline & \multicolumn{2}{|l|}{1 Joinpoint } & $-1.8^{*}$ & -2.2 to -1.5 & -10.8 & 0.00 \\
\hline \multirow[t]{2}{*}{ Female } & \multicolumn{2}{|c|}{ All period $1972-2017$} & $-1.0^{*}$ & -1.3 to -0.7 & -6.4 & 0.00 \\
\hline & \multicolumn{2}{|l|}{4 Joinpoints } & -1.4 & -3.5 to 0.7 & -1.3 & 0.20 \\
\hline
\end{tabular}

* Indicate that it is significantly different from zero at the alpha $=0.05$ 
Table 3 (on next page)

Crude rate, ASRC, and ASRW by sex for liver cancermortality in Qidong, 1972-2017 (per 10 ${ }^{5}$ ) 
1 Crude rate, ASRC, and ASRW by sex for liver cancer mortality in Qidong, 1972-2017 (per 10 ${ }^{5}$ )

\begin{tabular}{|c|c|c|c|c|c|c|c|c|c|c|c|c|}
\hline \multirow{2}{*}{ Year } & \multicolumn{4}{|c|}{ Male } & \multicolumn{4}{|c|}{ Female } & \multicolumn{4}{|c|}{ Total } \\
\hline & $\begin{array}{l}\text { No. of } \\
\text { Death }\end{array}$ & $\mathrm{CR}$ & ASRC & ASRW & $\begin{array}{l}\text { No. of } \\
\text { Death }\end{array}$ & $\mathrm{CR}$ & ASRC & ASRW & $\begin{array}{l}\text { No. of } \\
\text { Death }\end{array}$ & $\mathrm{CR}$ & ASRC & ASRW \\
\hline 1972 & 394 & 77.76 & 75.96 & 96.73 & 113 & 21.43 & 18.01 & 23.16 & 507 & 49.04 & 45.11 & 57.34 \\
\hline 1973 & 352 & 68.85 & 66.70 & 84.32 & 117 & 22.01 & 20.30 & 24.71 & 469 & 44.97 & 41.97 & 52.36 \\
\hline 1974 & 390 & 75.43 & 73.34 & 91.49 & 146 & 27.26 & 23.62 & 30.33 & 536 & 50.92 & 47.02 & 58.87 \\
\hline 1975 & 432 & 82.71 & 80.99 & 101.73 & 128 & 23.72 & 19.10 & 25.33 & 560 & 52.74 & 48.25 & 61.12 \\
\hline 1976 & 416 & 78.88 & 77.61 & 95.54 & 108 & 19.87 & 16.98 & 21.66 & 524 & 48.92 & 45.67 & 56.42 \\
\hline 1977 & 415 & 78.05 & 74.07 & 93.58 & 114 & 20.81 & 16.90 & 22.17 & 529 & 49.00 & 44.06 & 55.96 \\
\hline 1978 & 415 & 77.54 & 71.85 & 90.19 & 140 & 25.38 & 22.25 & 28.11 & 555 & 51.07 & 45.93 & 57.49 \\
\hline 1979 & 409 & 76.06 & 68.78 & 85.39 & 146 & 26.35 & 22.21 & 27.93 & 555 & 50.84 & 44.61 & 55.38 \\
\hline 1980 & 395 & 73.42 & 63.65 & 80.27 & 134 & 24.05 & 19.29 & 24.71 & 529 & 48.30 & 40.67 & 51.30 \\
\hline 1981 & 388 & 71.81 & 61.55 & 76.59 & 122 & 21.81 & 17.78 & 22.80 & 510 & 46.38 & 39.08 & 48.75 \\
\hline 1982 & 411 & 75.31 & 62.37 & 78.76 & 117 & 20.87 & 16.75 & 21.47 & 528 & 47.72 & 39.01 & 49.16 \\
\hline 1983 & 448 & 81.59 & 66.26 & 83.21 & 155 & 27.49 & 21.11 & 27.26 & 603 & 54.18 & 43.20 & 54.27 \\
\hline 1984 & 511 & 92.69 & 74.72 & 92.64 & 132 & 23.33 & 17.41 & 22.43 & 643 & 57.56 & 45.65 & 56.93 \\
\hline 1985 & 480 & 86.66 & 67.39 & 85.81 & 154 & 27.19 & 19.92 & 25.73 & 634 & 56.60 & 43.25 & 55.02 \\
\hline 1986 & 459 & 82.59 & 63.28 & 78.51 & 140 & 24.66 & 17.67 & 22.79 & 599 & 53.32 & 40.15 & 50.15 \\
\hline 1987 & 467 & 83.63 & 63.16 & 78.78 & 140 & 24.52 & 17.44 & 22.44 & 607 & 53.75 & 39.99 & 50.06 \\
\hline 1988 & 454 & 80.64 & 59.55 & 73.50 & 115 & 20.02 & 14.32 & 18.17 & 569 & 50.02 & 36.67 & 45.37 \\
\hline 1989 & 421 & 74.18 & 53.47 & 66.48 & 115 & 19.88 & 13.54 & 17.15 & 536 & 46.77 & 33.26 & 41.31 \\
\hline 1990 & 495 & 86.52 & 60.88 & 76.67 & 124 & 21.29 & 14.97 & 18.44 & 619 & 53.62 & 37.55 & 46.85 \\
\hline 1991 & 475 & 82.51 & 56.14 & 70.28 & 147 & 25.13 & 15.31 & 20.42 & 622 & 53.59 & 35.54 & 45.04 \\
\hline 1992 & 465 & 80.54 & 53.86 & 66.95 & 134 & 22.88 & 14.63 & 18.61 & 599 & 51.51 & 34.11 & 42.56 \\
\hline 1993 & 529 & 91.46 & 57.75 & 74.93 & 151 & 25.79 & 14.78 & 20.30 & 680 & 58.43 & 36.06 & 47.16 \\
\hline 1994 & 594 & 102.79 & 62.82 & 81.58 & 198 & 33.77 & 19.12 & 25.64 & 792 & 68.02 & 40.78 & 53.29 \\
\hline 1995 & 600 & 104.01 & 62.01 & 79.41 & 204 & 34.74 & 18.88 & 25.72 & 804 & 69.07 & 40.21 & 52.14 \\
\hline 1996 & 600 & 103.78 & 59.01 & 77.45 & 194 & 33.04 & 17.24 & 23.09 & 794 & 68.13 & 37.93 & 49.88 \\
\hline 1997 & 584 & 100.82 & 56.17 & 72.96 & 218 & 37.07 & 18.40 & 25.79 & 802 & 68.71 & 37.13 & 49.11 \\
\hline 1998 & 600 & 103.77 & 56.67 & 73.41 & 203 & 34.49 & 17.38 & 23.77 & 803 & 68.83 & 36.77 & 48.12 \\
\hline 1999 & 619 & 107.41 & 57.68 & 75.10 & 178 & 30.32 & 15.41 & 20.62 & 797 & 68.51 & 36.42 & 47.59 \\
\hline 2000 & 608 & 105.58 & 54.24 & 71.40 & 202 & 34.49 & 16.46 & 22.66 & 810 & 69.73 & 35.22 & 46.80 \\
\hline 2001 & 667 & 116.12 & 59.61 & 77.24 & 186 & 31.80 & 14.31 & 19.99 & 853 & 73.58 & 36.76 & 48.30 \\
\hline
\end{tabular}




\begin{tabular}{|c|c|c|c|c|c|c|c|c|c|c|c|c|}
\hline 2002 & 669 & 117.00 & 56.22 & 74.49 & 194 & 33.32 & 15.04 & 21.01 & 863 & 74.79 & 35.46 & 47.40 \\
\hline 2003 & 605 & 106.42 & 50.16 & 67.10 & 204 & 35.23 & 15.00 & 20.94 & 809 & 70.50 & 32.45 & 43.74 \\
\hline 2005 & 631 & 112.98 & 49.42 & 67.38 & 232 & 40.50 & 15.63 & 22.71 & 863 & 76.28 & 32.36 & 44.66 \\
\hline 2007 & 590 & 106.68 & 44.41 & 61.02 & 212 & 37.30 & 13.00 & 18.95 & 802 & 71.52 & 28.58 & 39.67 \\
\hline 2008 & 624 & 113.41 & 46.94 & 64.01 & 261 & 46.11 & 16.19 & 23.83 & 885 & 79.28 & 31.44 & 43.61 \\
\hline 2011 & 545 & 98.84 & 37.76 & 52.98 & 201 & 35.21 & 10.91 & 16.54 & 746 & 66.47 & 24.16 & 34.39 \\
\hline 2012 & 522 & 94.54 & 34.00 & 49.31 & 223 & 39.00 & 12.57 & 18.81 & 745 & 66.28 & 23.10 & 33.66 \\
\hline 2013 & 496 & 89.93 & 32.53 & 47.47 & 207 & 36.18 & 9.78 & 15.86 & 703 & 62.56 & 20.99 & 31.30 \\
\hline 2014 & 451 & 81.91 & 28.01 & 41.99 & 198 & 34.57 & 9.81 & 15.66 & 649 & 57.77 & 18.69 & 28.30 \\
\hline 2015 & 494 & 89.89 & 30.76 & 46.94 & 192 & 33.55 & 9.17 & 14.68 & 686 & 61.15 & 19.69 & 30.17 \\
\hline 2016 & 464 & 84.60 & 27.70 & 43.19 & 187 & 32.71 & 8.68 & 14.36 & 651 & 58.12 & 17.87 & 28.01 \\
\hline
\end{tabular}

2 
Figure 1

Natural death rate, mortality rates of cancer and of liver cancer in Qidong, 1958-2017

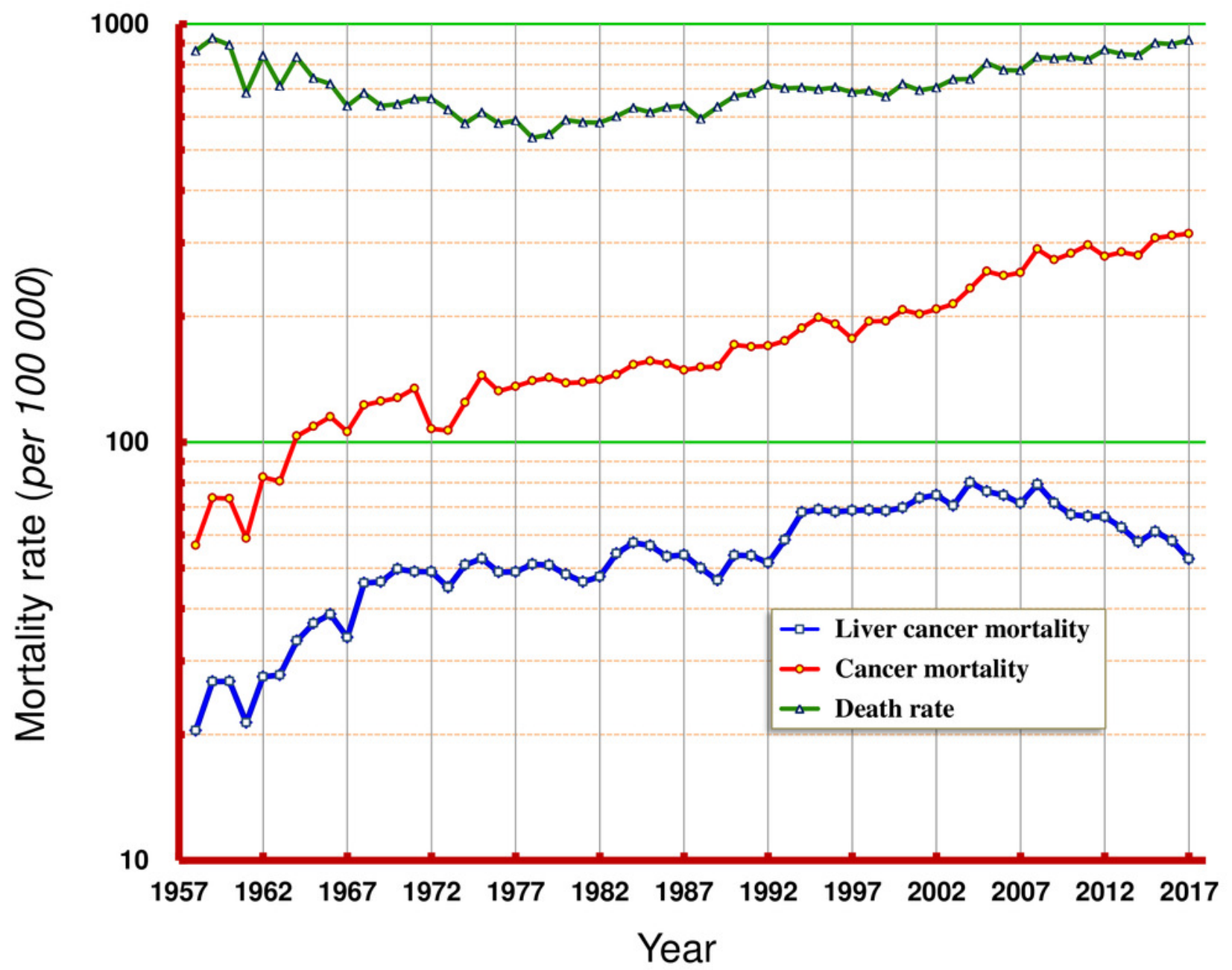

FIGURE 1 
Figure 2

AAPCmodels of WASR by sex for liver cancer mortality in Qidong, 1972-2017

AAPC models of WASR by sex for liver cancer mortality in Qidong, 1972-2017

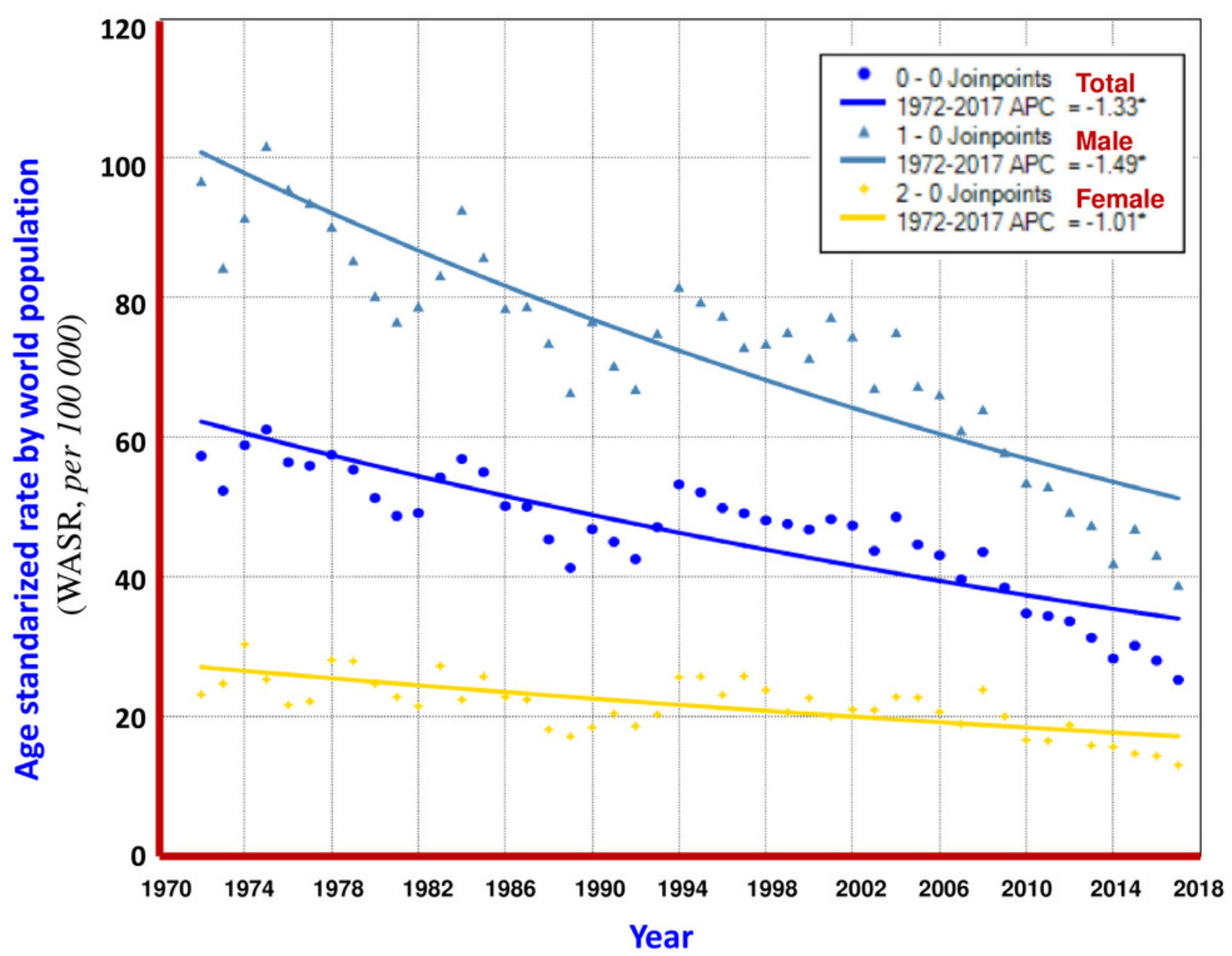

FIGURE 2 
Figure 3

The APC of liver cancer mortality in Qidong, 1972-2017

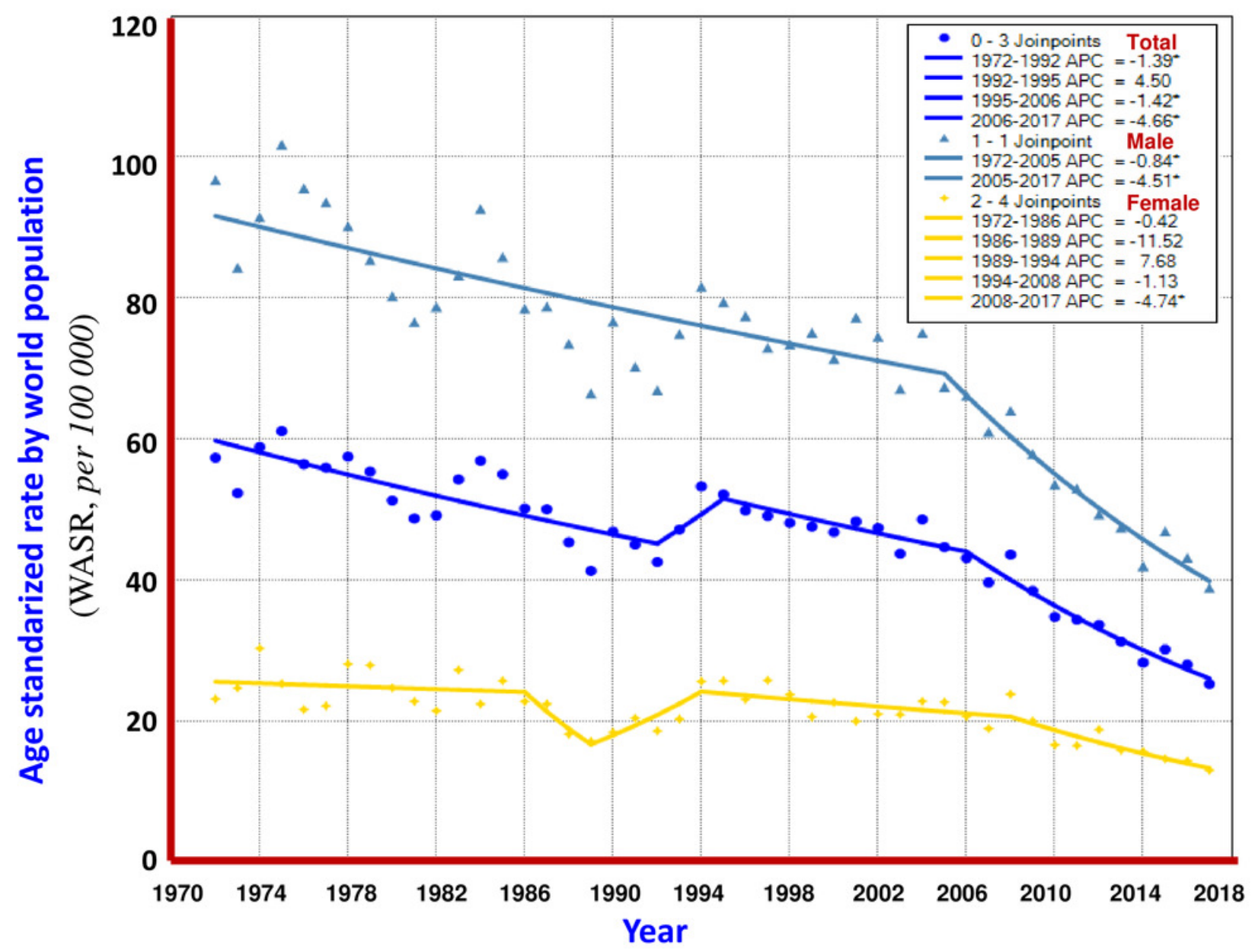

FIGURE 3 
Figure 4

The average ages of patients with liver cancer in Qidong, 1972-2017

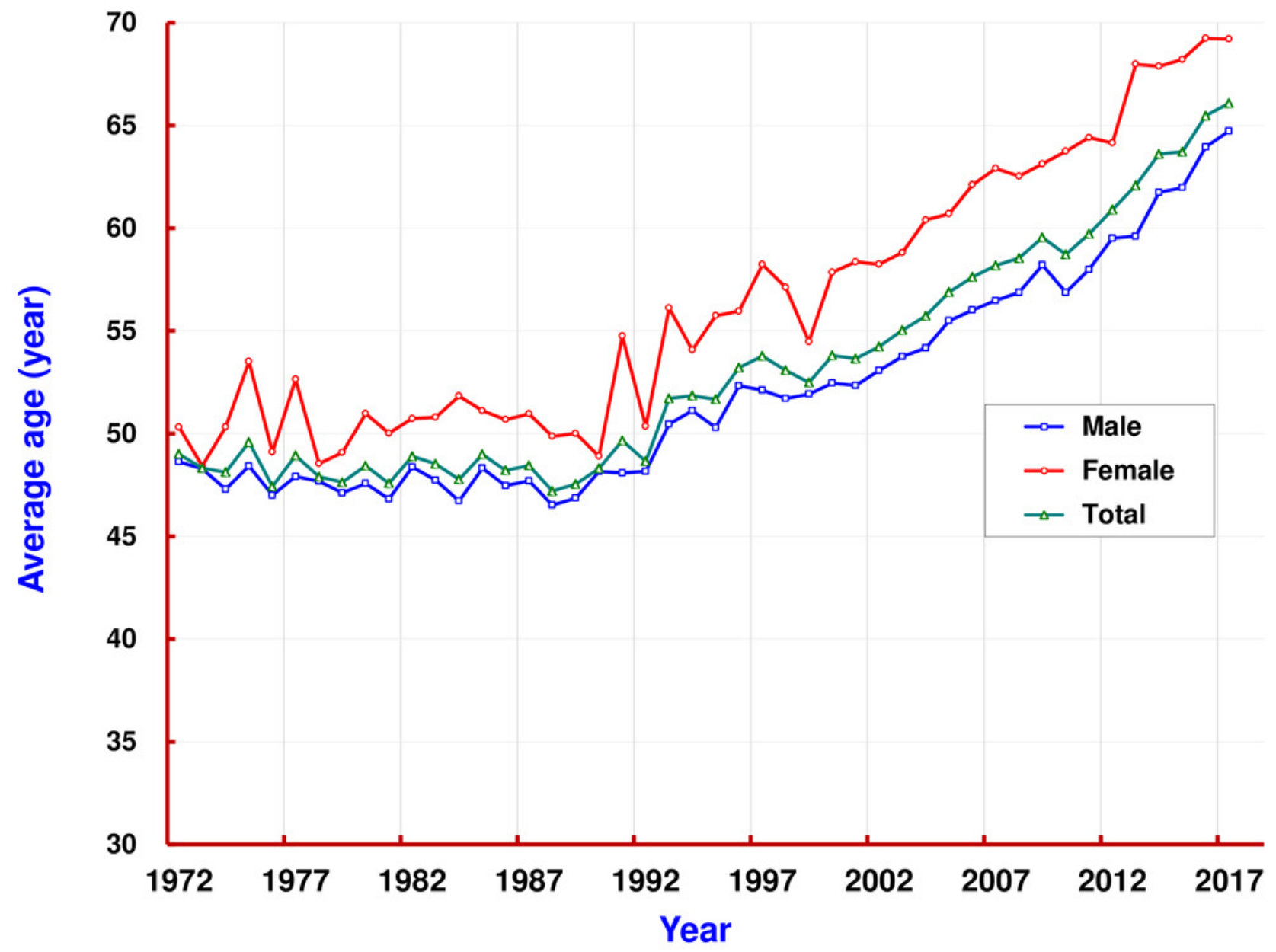

FIGURE 4 
Figure 5

Age-specific mortality rates of liver cancer by period in Qidong, 1972-2017

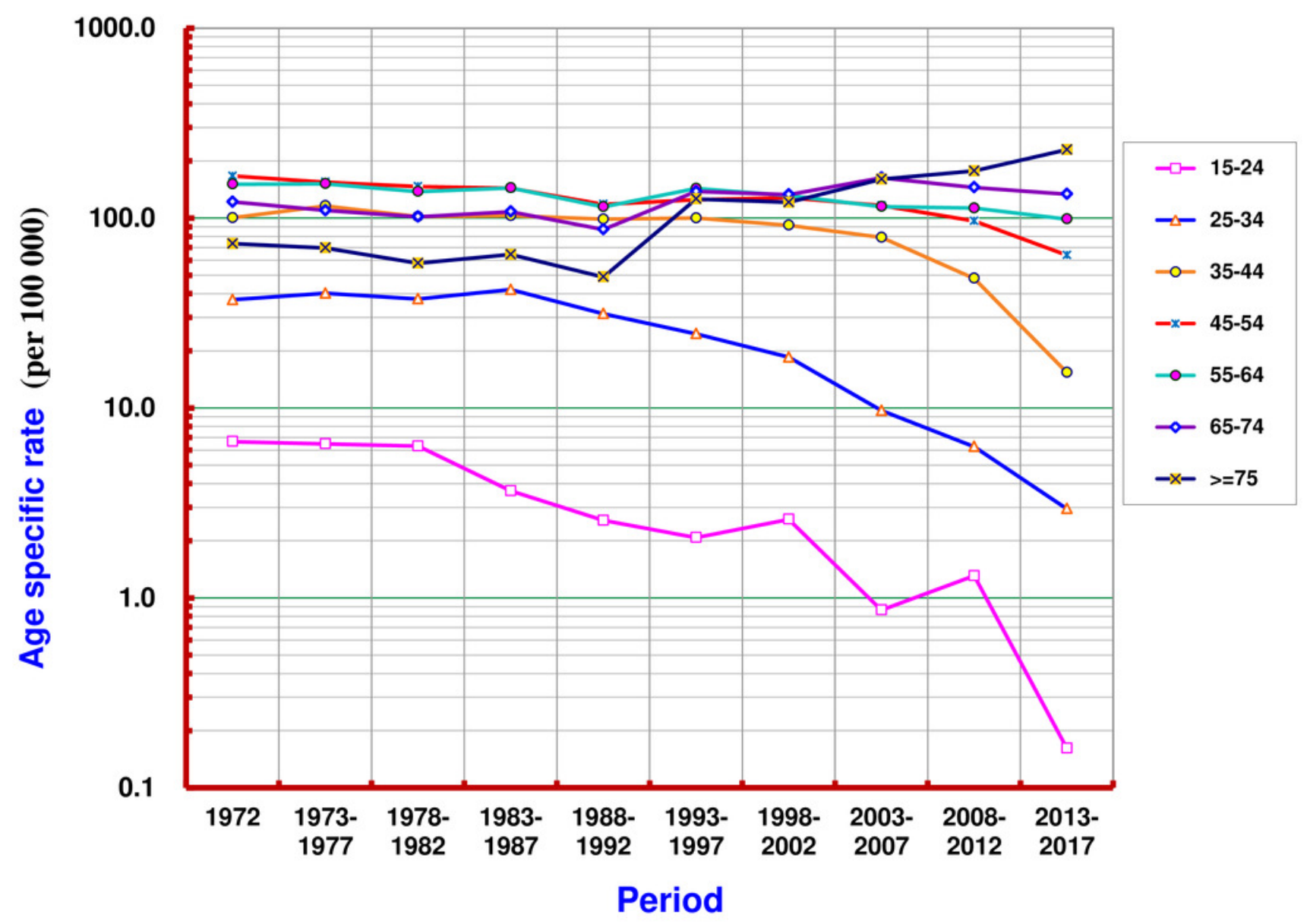

FIGURE 5 
Figure 6

AAPCs of mortality rates of liver cancer by age group in Qidong, 1972-2017

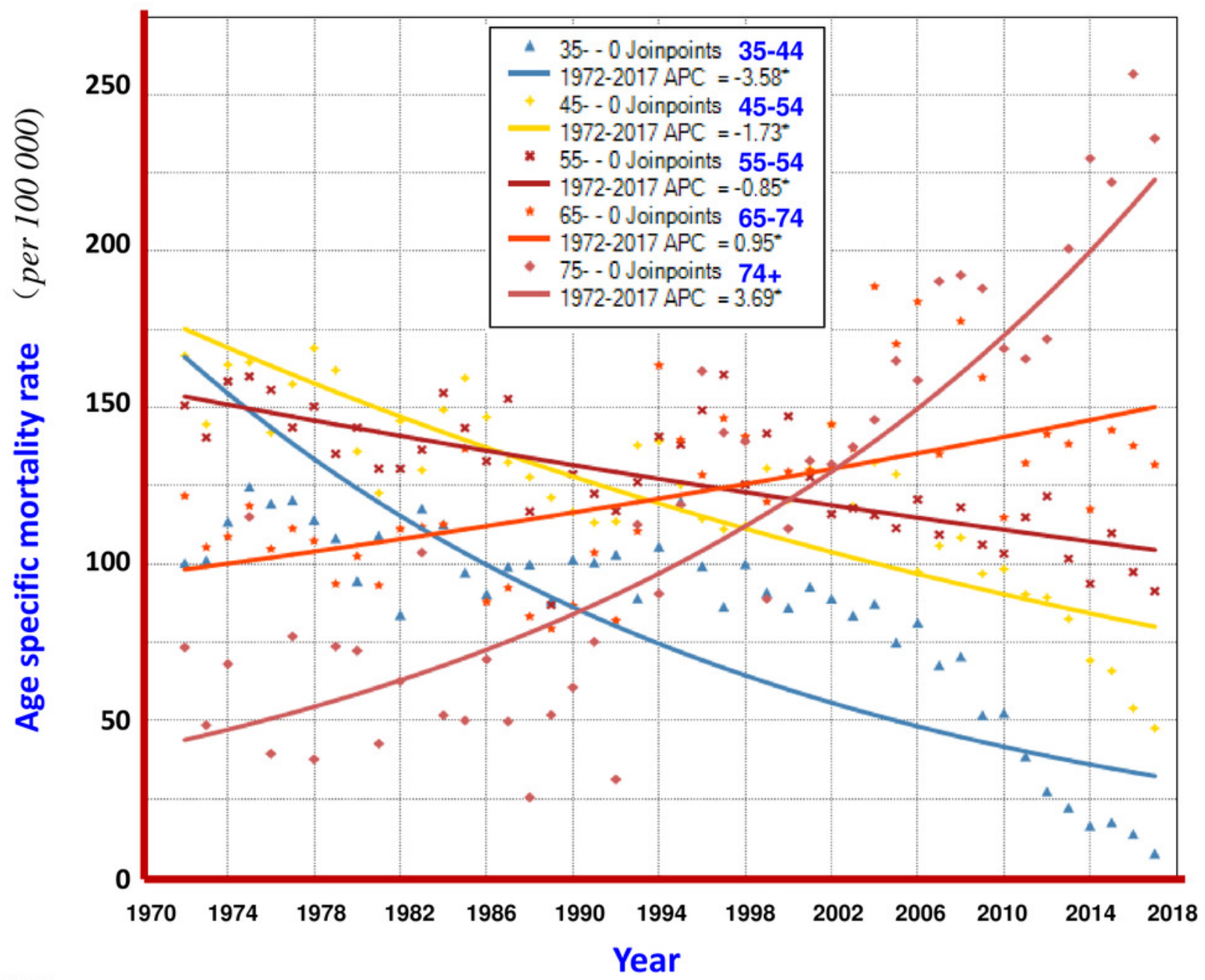

FIGURE 6 
Figure 7

Birth-cohort mortality rates of liver cancer in Qidong, 1972-2017

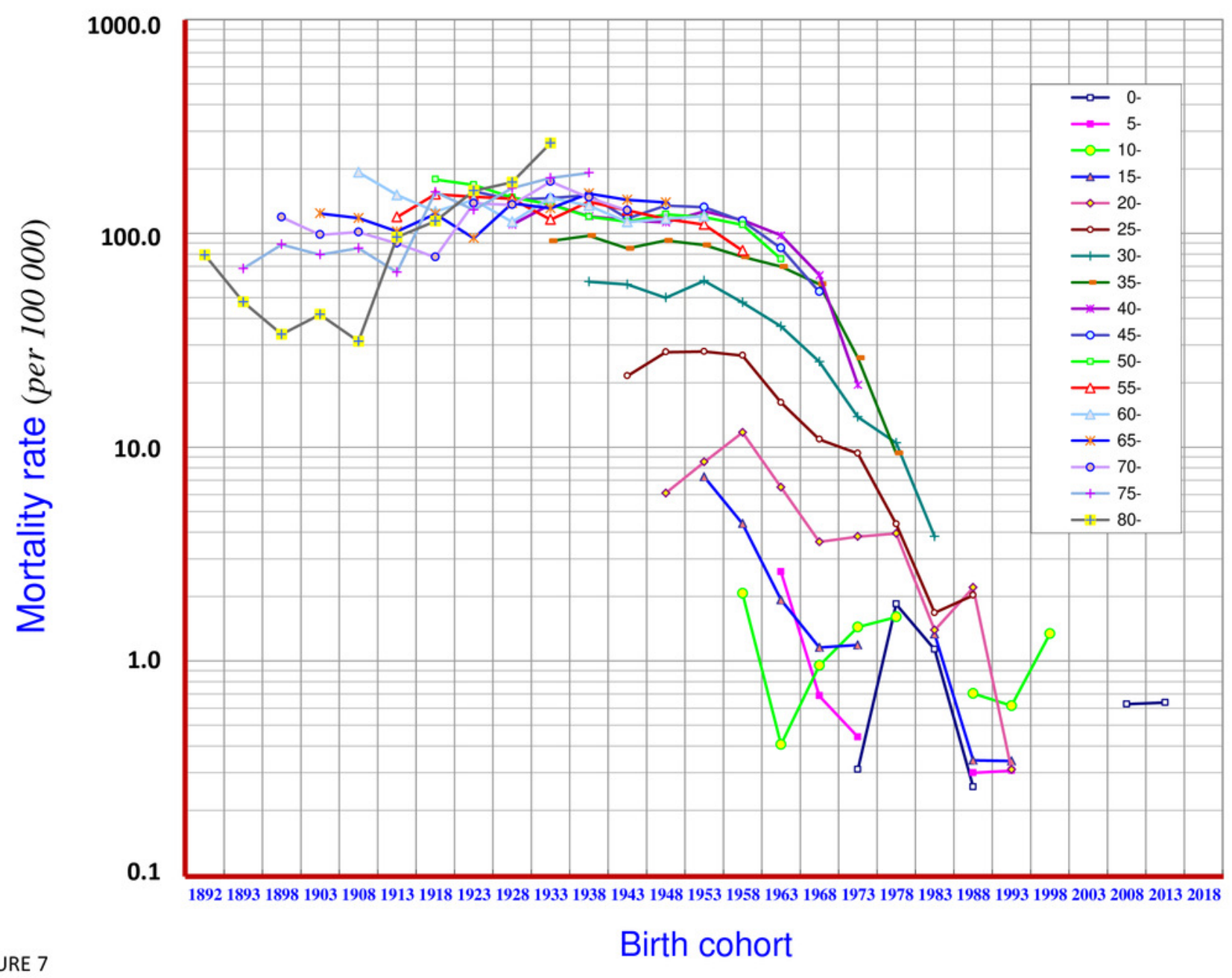

